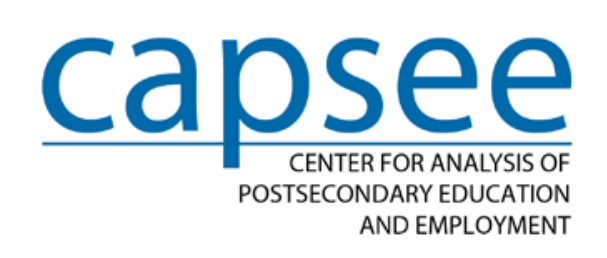

\title{
Examining the Earnings Trajectories of Community College Students Using a Piecewise Growth Curve Modeling Approach
}

\section{A CAPSEE Working Paper}

\author{
Shanna Smith Jaggars \\ Di Xu \\ Community College Research Center \\ Teachers College, Columbia University
}

April 2015

The research reported here was supported by the Institute of Education Sciences, U.S. Department of Education, through Grant R305C110011 to Teachers College, Columbia University. The opinions expressed are those of the authors and do not represent views of the Institute or the U.S. Department of Education.

For information about authors and CAPSEE, visit capseecenter.org 


\begin{abstract}
Policymakers have become increasingly concerned with measuring —and holding colleges accountable for-students' labor market outcomes. In this paper we introduce a piecewise growth curve approach to analyzing community college students’ labor market outcomes, and we discuss how this approach differs from Mincerian and fixed-effects approaches. Our results suggest that three assumptions underpinning traditional approaches may not be well founded. We then highlight how insights gained from the growth curve approach can be used to strengthen evolving econometric analyses of labor market returns, as well as to improve the accuracy and usefulness of the relatively simple models required by policymakers and practitioners.
\end{abstract}




\section{Table of Contents}

1. Introduction.......................................................................................................................................... 1

2. Traditional and Evolving Econometric Approaches .................................................................. 2

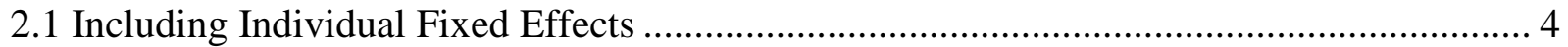

2.2 Controlling for Pre-Enrollment or During-Enrollment Earnings .................................... 4

2.3 Controlling for the Time Lapse Between College Exit and Final Earnings Outcome ......... 7

2.4 Drawbacks of Expanded Mincerian Approaches............................................................ 8

3. A Multilevel Growth Curve Approach .................................................................................. 9

4. Data and Descriptive Statistics ............................................................................................. 11

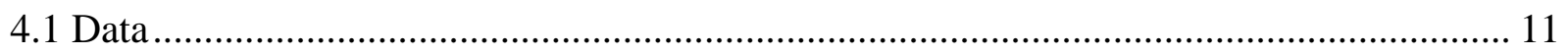

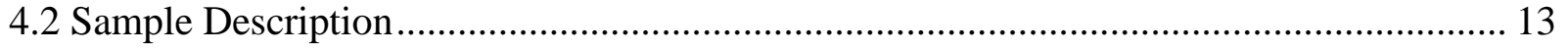

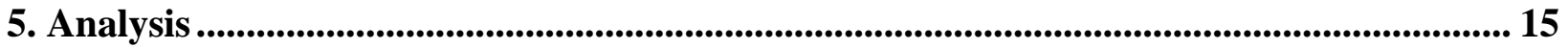

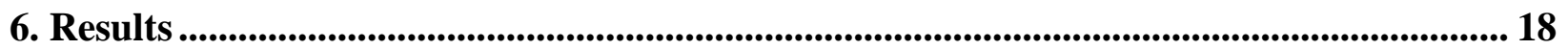

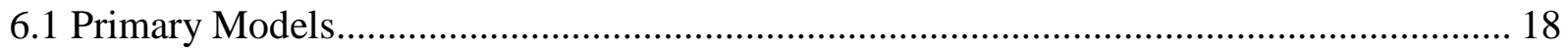

6.2 Comparing the Two-Piece and Three-Piece GCM Results .......................................... 22

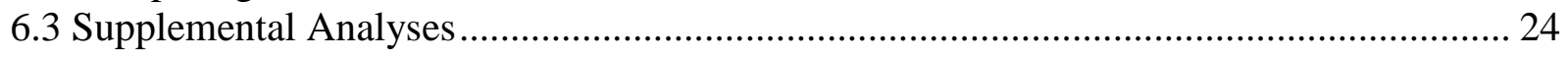

7. Implications for Traditional and Evolving Econometric Models..................................... 29

7.1. The Assumption That Across-Student Variation Is Constant Across Time ..................... 29

7.2. The Assumption of an Appropriate Counterfactual ..................................................... 30

7.3. The Assumption That the Impacts of an Award Are Fixed Over Time ........................... 31

8. Implications for Policy and Practice ......................................................................................... 32

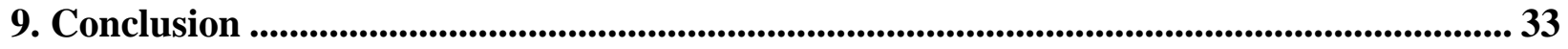

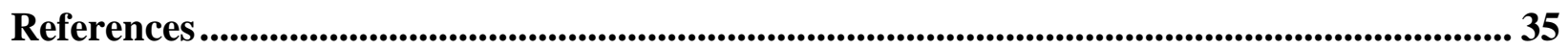





\section{Introduction}

Over the past decade, policymakers have become increasingly concerned with holding colleges accountable for their students' outcomes. As of 2013, more than 30 states were considering or enacting “performance-based” approaches to college funding (Jones, 2013; Kelderman, 2013), and several states with existing performance-based funding policies had recently strengthened them (Dougherty \& Reddy, 2013). As part of this trend, state and federal agencies are beginning to more closely examine college graduates' labor market outcomes, with some states integrating labor market outcomes into performance-based funding formulas (e.g., Florida Board of Governors, 2013; Jones, 2013; Minnesota State Legislature, 2013). Perhaps the most extreme example of this is in Texas, where public technical college funding is now based almost exclusively on graduates' earnings (Reeser, 2014; Texas Higher Education Coordinating Board, 2013).

In addition to using labor market outcomes in accountability and funding schemes, policymakers - as well as community and technical college practitioners-are considering how to supply prospective students with information regarding the labor market outcomes of various degrees and areas of study. Such information may help students better understand the economic costs and benefits of different programs of study and allow them to make more informed program choices. For example, California's community college system now provides students with an online tool allowing them to view graduates' median salaries by college and occupation (Perry, 2014).

The use of student labor market outcomes in accountability, funding, and student advising schemes, however, raises a host of practical methodological questions. For example, how long must states track graduates' labor market outcomes in order to accurately gauge the impact of degrees on earnings? Must states control for students' previous background or earnings prior to college entry? In general, states lean toward parsimony, simplicity, and relatively shortterm timeframes in their calculation of labor market outcomes. For example, under the Texas technical colleges funding formula, the state tracks graduates' earnings for five years, and compares the average annual salary to a full-time minimum wage salary in order to calculate the college’s “value added” (Texas Higher Education Coordinating Board, 2013). California Community Colleges' online tool calculates the median of graduates' earnings across five years of award recipients and displays median earnings at two years before, two years after, and five years after the award date (Perry, 2014).

Methodologists would certainly take issue with such simplistic approaches, which make no attempt to control for student selection into the level of degree or field of study. For example, a highly motivated and well-prepared student who earns an associate degree in a lucrative field may have higher earnings than a student with no college degree; yet the first student's high earnings could be due to his or her own pre-existing personal characteristics rather than to the degree itself. In order to control for students' pre-existing characteristics and to accurately trace 
the impacts of a degree across both the short- and long-term, economists have relied on increasingly complex and opaque models, as we will discuss in more detail below. Yet if policymakers, practitioners, and students cannot understand such analytic models or their results, then these models are unlikely to ever be applied in practical contexts (Bailey, Jaggars, \& Jenkins, 2015).

In this paper, we import an approach from developmental studies-a piecewise multilevel growth curve approach—-to analyze community college students' labor market outcomes. The

growth curve approach includes strong controls for students' pre-existing characteristics, but also provides a more transparent analysis and clearer results in terms of how degree awards impact students' earnings over time. In section 2, we review the traditional Mincerian approach to analyzing labor market returns to college credentials, the difficulties involved in drawing conclusions from this cross-sectional analysis of an inherently longitudinal process, and increasingly popular additions to the Mincerian equation (such as student fixed effects) that attempt to work around those difficulties. In section 3, we introduce the multilevel growth curve approach, which is specifically designed to analyze longitudinal processes and thus can more elegantly address the difficulties discussed in section 2 . In sections 4 and 5 , we analyze a statewide dataset using the growth curve approach and present the results. Finally, in section 6 we discuss how insights gained from the growth curve approach can be used to strengthen traditional and evolving econometric approaches to the calculation of labor market returns, as well as to improve the accuracy and usefulness of the relatively simple models required by policymakers and practitioners.

\section{Traditional and Evolving Econometric Approaches}

Among the dozens of analyses of labor market returns to vocational certificates and associate degrees performed across the 1990s and 2000s, almost all used a Mincerian approach (see Belfield \& Bailey, 2011), named after the pioneering labor economist Jacob Mincer. Such analyses focus on students' earnings at a single point in time; at that given time point, Mincerian models compare the earnings of students who have earned an award and those who have not, while controlling for background characteristics, as shown in Equation 1:

$$
Y_{i, 2012}=\alpha+\beta_{1} \cdot \operatorname{Award}_{i}+\beta_{2} \cdot \exp _{i}+\beta_{3} \cdot \exp _{i}^{2}+X_{i}+\varepsilon_{i}
$$

In Equation 1, the dependent variable is the student's earnings (often in log form) at a given time point. Award $d_{i}$ represents a vector of dummy variables indicating the student's highest education award by that time point; $\exp _{i}$ is a measure of a student's prior work experience, along with the quadratic form of this term to reflect Mincer's (1974) formulation that earnings increase with work experience but at a declining rate; and $X_{i}$ refers to a vector of other individual characteristics, which vary depending on the observables available in the given dataset. 
In a representative example, Bailey, Kienzl, and Marcotte (2004) performed Mincerian analyses of returns to community college credentials using three separate federal survey datasets (High School \& Beyond, or HS\&B; the Beginning Postsecondary Students Longitudinal Study of 1989, or BPS89; and the National Education Longitudinal Study of 1988, or NELS88). Each dataset followed a defined cohort of students across a defined timeframe; for example, HS\&B sampled students who were high school sophomores in 1980 and followed them until 1992, and BPS89 sampled students who were entering college for the first time in 1989-1990 and followed them until 1993. Analyses focused on earnings in the final time point, comparing those of award earners and award non-earners while controlling for variables such as race/ethnicity, parental education, and educational test scores.

Classic Mincerian models are subject to the same criticism that plagues all traditional ordinary least squares (OLS) approaches: while the model may control for observable sources of student selection into degree programs, it cannot control for unobservable sources of selection, such as individual ability. Moreover, the survey datasets available to early researchers typically did not contain information on an observable that was potentially quite important: the student's prior earnings.

In addition, while a Mincerian model's earnings outcome seems concretely fixed in time (e.g., 1993 in the Bailey et al., 2004, study), it may in fact be quite variable across students vis-àvis the timing of their college entry and exit. For example, even if we assume that all of Bailey et al.'s HS\&B college-goers entered college in 1983 (surely a false assumption for many students), some entered short certificate programs while others entered longer term degree programs. In addition, while some community college award earners attend full-time and graduate on time, the majority of community college students attend part-time, "stop out" for a semester or two, or otherwise do not earn their award on time (Crosta, 2014; Horn \& Neville, 2006). Accordingly, at the 1993 time point, some award earners in Bailey et al.'s study could have earned a college certificate nearly a decade ago, while others could have earned an award within the past year. If we assume that the effect of earning a degree is fixed across time, then such variation in the time lapse between an award and its earnings outcome is not problematic. However, in a study of displaced workers in Washington State who returned to community college to re-train, researchers found that workers' earnings tended to be depressed immediately after leaving college, before rising again across the long-term (Jacobson, LaLonde, \& Sullivan, 2005).

More recent studies of labor market returns to community college credentials have attempted to address these shortcomings of the Mincerian approach by taking fuller advantage of the panel data provided by federal longitudinal surveys and by making use of a new source of longitudinal data—state administrative datasets — which typically feature student transcript records linked to state unemployment insurance data. Longitudinal datasets have allowed economists to expand the Mincerian approach in three ways: by (1) controlling for unobservable student characteristics that are constant over time through individual fixed effects, (2) including controls for pre-enrollment or during-enrollment earnings, and (3) controlling for the time lapse between college exit and the time point of the final earnings measurement. 


\subsection{Including Individual Fixed Effects}

Although a standard Mincerian equation includes a rich set of individual characteristics, it cannot control for unobserved influences on individual earnings - including psychological characteristics such as motivation - which may influence both educational outcomes and earnings. Longitudinal datasets, because they typically contain quarterly or annual earnings records across a time span of several years for students, provide sufficient degrees of freedom for analysts to include individual student fixed effects in models of labor market returns. Such models effectively control for all student characteristics (whether observed or unobserved) that remain constant across students across time (Ashenfelter \& Card, 1985; Wooldridge, 2002). Equation 2 represents the typical student fixed effects approach used to estimate labor market returns to college awards:

$$
Y_{i j}=\alpha_{i}+\beta_{1} \operatorname{Award}_{i j}+X_{i j}+\pi_{i}+\mu_{i j}
$$

The outcome $Y_{i j}$ represents earnings for individual $j$ at quarter $i ; \alpha_{j}$ represents individual fixed effects, which include all observed and unobserved individual characteristics that are constant over time, and $A w \operatorname{ard}_{i j}$ represents dichotomous treatment indicators of whether individual $j$ had earned an award as of time $i$. While the fixed-effects approach controls nicely for time-invariant student characteristics, it cannot control for time-varying characteristics that influence both award attainment and earnings. Accordingly, fixed-effects models also typically include a vector of individual characteristics $\left(X_{i j}\right)$ that vary by time (e.g., whether student $j$ is enrolled in quarter $i)$, as well as fixed effects for the quarter or year of measurement $\left(\pi_{i}\right)$, which control for time-varying economic conditions that affect all students similarly at a given time point. For example, in the earliest paper using a fixed-effects approach to estimating community college returns, Jacobson et al. (2005) focused on workers in Washington State who had been permanently laid off between 1990 and 1994, using quarterly unemployment insurance records that followed workers from 1987 to 1995, along with information about community college participation until 1996. Time-varying controls included quarterly fixed effects, student $j$ 's enrollment status in quarter $i$, the number of courses taken by student $j$ in quarter $i$, and interactions between fixed student demographics (e.g., gender or year of layoff) and these timevarying effects.

In addition to controlling for time-invariant unobservables and time-varying observables, individual fixed-effects models also implicitly control for students' pre-enrollment or duringenrollment earnings, as we will discuss in the next section.

\subsection{Controlling for Pre-Enrollment or During-Enrollment Earnings}

Most community college students are active in the workforce both before and during their college enrollment: according to federal estimates, 35 percent of community college students are aged 30 or older, and about 79 percent work while enrolled, with an average workweek of 32 hours (Horn \& Neville, 2006). These students' pre-enrollment and during-enrollment earnings 
ought to reflect their accumulated human capital, as well as other unobservables such as motivation, which would presumably impact both their choice of degree program and their eventual post-award earnings.

The advent of detailed longitudinal state administrative datasets theoretically allowed economists using the classic Mincerian approach (i.e., Equation 1) to include pre- or duringenrollment earning information in the vector $X_{i}$ in order to estimate the "value added" by a community college award. Of the two published studies using state community college administrative data that included a Mincerian approach, one study included four quarters of preenrollment earnings as a control in their Mincerian specification (Jepsen, Troske, \& Coomes, 2014), while the other included neither pre- nor during-enrollment earnings (Liu, Belfield, \& Trimble, 2015). The first study's choice was based on Ashenfelter's (1978) finding that some employees have depressed earnings in the year prior to training entry, which would bias upward the estimated training effect; moreover, Jepsen et al.'s descriptive data showed an average earnings dip that seemed to begin approximately three quarters prior to college entry. Perhaps Liu et al. (2015) did not address this issue in their Mincerian model because they also presented a fixed-effects model later in the paper; the authors may also have been reluctant to choose specific pre- or during-enrollment earnings time points as controls in the Mincerian $\mathrm{X}_{i}$ because it was not entirely clear which time points were most appropriate to include as controls. Indeed, Ashenfelter and Card (1985) found wildly varying estimates of the effect of training depending on which pre-training year is chosen as the "base year" for comparison.

The methodological challenge identified by Ashenfelter and Card (1985) has been echoed in the literature of many other fields that focus on measuring change across time using longitudinal data. As Willett (1997) summarized, early longitudinal methodologists conceived of an individual's change across time in an outcome (such as earnings) in terms of a single increment: the difference between "before" and "after." Willett argued, however, that "individual change takes place continuously over time and must not be viewed as a 'before' and 'after' phenomenon. In fact, it is our failure to perceive of change as a continuous process of individual development over time that has hamstrung the creation of decent statistical methods for its measurement" (pp. 213-214). Willett pointed out that individuals follow different trajectories of growth across time and that these trajectories crisscross with one another; accordingly, depending on which pre-intervention time point is considered the "initial" time point, the correlation between the initial-status time point and the increment of change may fluctuate between positive, negative, or null.

Perhaps in recognition of the futility of establishing a "true" initial-status time point, recent studies of labor market returns to community college credentials have downplayed or even entirely discarded the classic Mincerian equation in favor of the individual fixed-effects approach, which is thought to more adequately control for the full vector of pre- or duringenrollment earnings (e.g., Bahr, 2014; Dadgar \& Weiss, 2014; Jacobson et al., 2005; Jepsen et al., 2014; Liu et al., 2015; Xu \& Trimble, 2014). The fixed-effects approach (Equation 2) features the inclusion of $\alpha_{j}$ controls for fixed across-student variation in earnings; under the 
assumption that time-varying across-student variation is also controlled, the only remaining source of variance is within-student variation in earnings, and thus term $\beta_{1}$ reflects the withinindividual change in earnings from pre- to post-award. As Jepsen et al. (2014) pointed out, $\beta_{1}$ is thus similar to a difference-in-differences estimator, comparing the change in earnings from preto post-college exit between award earners and those who exited college without an award. This approach may seem to assuage Willett's (1997) concerns regarding the choice of a single "before" and "after" time point, as the pre- and post-periods each contain multiple data points for earnings. That is, the model essentially compares the student's average level of pre- and duringenrollment earnings to his or her average level of post-enrollment earnings, after removing observed factors that may distort the student's "true” level of earning potential in each periodby, for example, removing “Ashenfelter dip” effects by including an indicator for the quarters immediately prior to enrollment, removing the opportunity costs of school attendance by including an indicator for quarters of enrollment, and removing the effects of economic shocks by including quarterly fixed effects.

Yet the individual fixed effect approach, despite its merits, still fails to address Willett's (1997) central objection to pre-post models of change: that growth across time is a continuous process of intra-individual growth, which cannot be accurately modeled as a one-time pre-post increment of change. Indeed, criticisms of the individual fixed-effects approach and the related difference-in-differences approach have focused on the fact that individuals' pre-award earnings trajectories are so strongly varied that they will necessarily introduce time-varying across-student variation for which it is quite difficult to control (e.g., Ashenfelter \& Card, 1985; Heckman, Lalonde \& Smith, 1999). Recognizing this problem, economists using fixed-effects models to estimate returns to community college credentials have attempted to control for such variation in creative ways. For example, Jacobson et al. (2005) noted that job loss affects students' earnings trajectories across the several quarters preceding and following the displacement; thus the authors include not only dummy variables capturing the number of quarters relative to job loss, but also interact those terms with characteristics such as age and industry of employment in order to allow the temporal effects of job displacement to unfold differently across these demographic groups. The authors note that, "altogether, our specification of the effect of displacement on earnings is quite flexible, containing approximately 150 parameters” (p. 282). Other studies treat the passage of time as a continuous variable, and interact it with selected student characteristics in order to allow the general trend of earnings across time to vary across student groups (e.g., Bahr, 2014; Dadgar \& Weiss, 2014). Dadgar and Weiss noted that their models are not sensitive to the inclusion of these trend variables, "presumably because the Individual Fixed Effects is doing the 'hard work' of identification.” However, the time trends' lack of usefulness could equally be due to poor choices in terms of the functional form of the trends and their variation across students (Abadie, 2005). The approach of interacting time trends or time-based characteristics (e.g., timing of displacement) with selected student characteristics assumes not only that the typical "shape" of change across time is appropriately captured by the time variables, but also that the shape of students' earnings trajectories is relatively homogeneous 
within each selected grouping and relatively heterogeneous between groupings. However, this assumption may not be valid, and was not explicitly tested in the studies reviewed here.

A final challenge of the individual fixed-effects approach—or indeed any other approach to controlling for pre-enrollment and during-enrollment earnings - is that pre- and duringenrollment controls are valid only if they reflect students' underlying human capital and wageearning potential. The assumption of validity is likely justified for older students who have entered a particular vocational or professional field, but may be less justified for young students from higher income families, who may be working in relatively temporary positions (such as retail or food services) in order to earn “extra” money for school. For example, Dadgar and Weiss (2014) found that, among community and technical college students in Washington State (over half of whom were 19 or younger), the correlation between pre-entry and post-exit wages was quite small $(r=0.04)$, although it was substantially larger among students who worked more than 1,000 hours in the year prior to enrollment $(r=0.13)$ than among those who did not $(r=$ 0.03).

\subsection{Controlling for the Time Lapse Between College Exit and Final Earnings Outcome}

In the first study to apply the fixed-effects method to the analysis of the returns to community college credentials, Jacobson and colleagues (2005) noted that the short-run impact of a credential appeared to be depressed in comparison with its long-run impact. To deal with this problem, the researchers included in their model a specification of time-since-exit, $\left(\frac{1}{t_{\text {-leave }}}\right)$, which was equal to 1 in the quarter immediately after a student's exit from college and iterated toward 0 across the long term, thus allowing the model's coefficients for awards to represent long-run impacts after controlling for short-run deviations. Despite Jacobson et al.'s observation, other studies of returns to community college credentials conducted over the next decade have entirely ignored the issue of time-since-exit.

This omission is rather puzzling, given that researchers using state administrative data typically have information regarding when each student entered and exited from college. While studies of community college returns in the past decade have typically provided basic information regarding the time lapse between student entry and the final measurement of earnings, none have provided information on the average time lapse (or the variation across students in time lapse) between exit and the final measurement. Moreover, only one study provided information on how the lapse between entry and final measurement affected the estimation of results: Liu et al., (2015) performed three supplementary Mincerian analyses estimating the returns to community college awards at five, seven, and nine years after first college entry. Liu and colleagues found that returns to awards grew substantially between five to seven years post-entry, with more moderate growth between seven and nine years post-entry. For example, women's estimated returns to an associate degree grew from $\$ 1,362$ per quarter at five years post-entry to $\$ 1,905$ at seven years and $\$ 2,136$ at nine years. 
At first blush, Liu et al.’s (2014) results imply that the impact of earning an associate degree follows a quadratic trend, with earnings increasing sharply for a few years before moderating across the long term. However, the story may not be so straightforward, given that only a slim minority of community college students graduate "on time" - that is, within, typically, two years. According to federal data, community colleges' graduation rate for firsttime full-time students is approximately 12 percent at two years post-entry, 22 percent at three years, and 28 percent at four years (Horn, 2010; Snyder \& Dillow, 2012). Graduation rates may continue to increase across subsequent years: A national survey estimated that six years after entry, 34 percent of community college students have earned a credential (either from a community college or four-year institution), while an additional 20 percent are still enrolled (Radford, Berkner, Wheeless, \& Shepherd, 2010). Accordingly, the changing results across time in Liu et al.'s (2014) study could be due to a change in the mix of awardees at the given time point. For example, it is possible that associate degree students who graduate fairly quickly are clustered in fields that yield strong earnings growth over time, while students who require many years to earn an associate degree are clustered in fields that yield flatter earnings, which then depresses the longer-term estimate for all associate degree awardees.

In general, as Bahr (2014) has pointed out, a lack of controls for time-since-exit results in estimates of average returns across post-award time. However, given the unknown and unreported variation in the length of post-award time across students in extant studies, we cannot identify the trajectories underlying "average" returns. More importantly, we cannot identify whether different types of awards result in different post-award earnings trajectories. For example, perhaps some credentials yield an immediate "bump" in income but no additional growth across time, while others accelerate income growth across time. Without an understanding of these trajectories, policymakers and practitioners have little guidance regarding how long is "long enough" to follow graduates' earnings across time, and students themselves cannot adequately plan for the short-term and long-term financial implications of their schooling choices.

\subsection{Drawbacks of Expanded Mincerian Approaches}

In summary, Mincerian models - even given their recent expansions using the fixedeffects approach-remain limited in their ability to explain students' changes in earnings across time. Both the traditional and expanded approaches focus on estimating a single pre-post "increment" of change, rather than on estimating how a credential changes an individual's trajectory of earnings (Willett, 1997). In order to estimate this single increment, many fixedeffects models include a large and complex array of interactions between characteristics of time and student, although the extent to which these adequately control for cross-student variation in pre-award earnings trajectories - and thus meet the identifying assumption of the fixed-effects model-remains unknown. Moreover, even if some models do provide adequate controls for identification, practitioners and policymakers can neither understand nor replicate such complex models and thus may ignore them entirely when writing formulas for policy purposes. Finally, 
because they focus on a single effect, expanded Mincerian approaches cannot differentiate between short-term bumps in income versus longer term income growth. In the next section, we discuss an alternative approach, multilevel growth curve modeling (GCM), which helps address the limitations we have discussed thus far.

\section{A Multilevel Growth Curve Approach}

GCM has become the preferred approach for measuring change across time within many academic fields that study individual development using detailed longitudinal datasets, such as biostatistics, educational statistics, and psychometrics (e.g., McArdle \& Epstein, 1987; Raudenbush \& Bryk, 2002; Singer \& Willett, 2003; Zeger \& Liang, 1986). ${ }^{1}$ The conceptual foundation of GCM is simple: each individual student's trajectory is estimated based on the data available for that student, resulting in an intercept and growth term for each student. In the field of labor market returns, Ashenfelter and Card (1985) used the same conceptual approach: they estimated individual earnings trajectories for each trainee in their sample and found that including these pre-training trajectories vastly improved model fit compared with their traditional difference-in-differences model. Indeed, they noted that "the cross-sectional variance of the individual-specific trend in earnings ... is very precisely estimated" (p. 657)—that is, the model more appropriately met the key identifying assumption of both the fixed-effects and difference-in-differences approach. Despite Ashenfelter and Card's insight, however, the individual trajectory approach has not been adopted in subsequent studies of labor market returns to community college credentials.

Early followers of the GCM concept often began with a simple OLS-based approach, creating a dataset containing each student's estimated intercept, linear slope, and often quadratic slope of change across time, with each estimate based on the student's own vector of longitudinal data. These student-level growth "outcomes" could then be predicted from other student-level characteristics, such as race/ethnicity, allowing researchers to understand how the shape of growth differed across student groups (Burstein, Linn, \& Capell, 1978). With the advent of more sophisticated multilevel modeling techniques in the 1980s, individual students' growth parameters could be more efficiently estimated using random-coefficient regression models (Raudenbush \& Bryk, 2002). For the sake of conceptual clarity, the resulting equations are typically written separately, with Level 1 modeling variation across time points within students and Level 2 modeling variation across students, as in Equation 3:

\footnotetext{
${ }^{1}$ Across disciplinary fields, GCM goes by many different names, including hierarchical linear modeling (HLM) and latent growth curve analysis (LGCA).
} 
Level 1: $Y_{i j}=\beta_{0 j}+\beta_{1 j}\left(\right.$ Time $\left._{i j}\right)+\mu_{i j}$

Level 2: $\beta_{0 j}=\beta_{00}+\beta_{01} X_{j}+\varepsilon_{0 j}$

$$
\beta_{1 j}=\beta_{10}+\beta_{11} X_{j}+\varepsilon_{1 j}
$$

In this simple example, $Y_{i j}$ represents the earnings for student $j$ at time point $i, \beta_{0 j}$ represents $j$ 's estimated intercept, $\beta_{1 j}$ represents $j$ 's estimated linear slope of change in earnings across time, and $\mu_{i j}$ captures the error between $j$ 's estimated and actual earnings at each time point $i$. The student-level intercept $\beta_{0 j}$ is estimated as a function of the overall intercept across all students $\left(\beta_{00}\right)$ and a vector of other student-level characteristics $\left(X_{j}\right)$, with $\varepsilon_{0 j}$ capturing the deviation between $j$ 's estimated intercept and the overall model intercept. The term $\varepsilon_{0 j}$ is typically assumed to be normally distributed across students, with variance $\tau_{00}$. The student-level slope $\beta_{1 j}$ is similarly estimated, with $\varepsilon_{1 j}$ having a variance $\tau_{11}$, and with the student-level intercepts and slopes having a covariance $\tau_{01}$.

Substituting the Level 2 equations into the Level 1 parameters yields a combined presentation (shown in Equation 4), which clarifies that $\beta_{11}$ effectively serves as an interaction term:

$$
Y_{i j}=\beta_{00}+\beta_{01} X_{j}+\beta_{10}\left(\text { Time }_{i j}\right)+\beta_{11}\left(\text { Time }_{i j}\right) \times X_{j}+\varepsilon_{0 j}+\varepsilon_{1 j}+\mu_{i j}
$$

Equation 4 also makes clear that, rather than estimating separate intercept and slope parameters for each student, the model must estimate only a small set of fixed parameters (e.g., $\beta_{00}, \beta_{01}$ ), variances for each of the three random error terms $\mu_{i j}, \varepsilon_{0 j}$, and $\varepsilon_{1 j}$, and the covariance between the two student-level random effects. In addition to this parsimony, GCM provides other benefits in terms of parameter estimation. For example (using Equation 3's notation), estimates of $\beta_{0 j}$ and $\beta_{1 j}$ will vary somewhat from OLS estimates derived strictly from an individual $j$ 's vector of data, because GCM "borrows strength" from the full array of $i j$ using a Bayesian estimator; student-level estimates that are very precise (e.g., due to a large number of available $i$ ) borrow less strength, while those that are less precise borrow more strength, resulting in more accurate estimates for $\beta_{0 j}$ and $\beta_{1 j}$ than would be possible using $j$ 's data alone (Raudenbush \& Bryk, 2002).

GCM allows for wide flexibility in the specification of the functional form of growth across time. Analysts may include linear, quadratic, or higher-order polynomial functions; quarterly fixed effects; or other characteristics of time such as the "timing of displacement" terms specified in Jacobson et al. (2005). When the growth trajectory is thought to be discontinuous, analysts may also consider a "piecewise" growth curve model (PGCM). Piecewise models allow the division of $j$ 's timeline into multiple stages or phases, along with the estimation of a new intercept and slope within each phase. The PGCM approach seems to lend itself well to analyzing returns to community college credentials: students' pre-enrollment 
earnings trajectories may be interrupted by their schooling, creating a distinct during-enrollment trajectory, followed by yet another new trajectory in the post-exit period.

In this paper, we present an application of the PGCM to the analysis of returns to community college credentials. By estimating pre-enrollment, during-enrollment, and post-exit trajectories for each student, we are able to more clearly delineate how awards affect students' earnings trajectories - and in particular, the extent to which each type of award provides an immediate "bump" in earnings versus an increase in the growth of earnings across time.

\section{Data and Descriptive Statistics}

\subsection{Data}

To explore variation in piecewise wage trajectories across different types of community college awards, we analyzed student unit record administrative data from the Virginia Community College System (VCCS) matched with Unemployment Insurance (UI) data from Virginia and neighboring states from the first quarter of 2005 to the first quarter of $2013 .^{2}$ We focused on first-time college students who initially enrolled during the fall of 2006, 2007, or 2008, therefore including 1.5 to 3.5 years of pre-enrollment earnings and 4.5 to 6.5 years of postentry earnings. ${ }^{3}$ Similar to other studies using state higher education system administrative data, all students in our sample entered college; accordingly, the labor market return to a given award (including the credits inherent in that award) is estimated in comparison with students who entered college and may have earned some college credits but did not receive an award by the end of the tracking period (e.g., Bahr, 2014; Dadgar \& Weiss, 2014; Jepsen et al., 2014; Liu et al., 2015; Xu \& Trimble, 2014).

The VCCS administrative data contain student demographics, complete transcript records across all 23 community colleges in the state, financial aid information, intended major and degree at college entry, and credentials obtained. In terms of demographics, the dataset provided information on each student's gender, race/ethnicity (Asian, Black, Hispanic, White, or Other), age at college entry, and a variety of academic background variables, including whether the student was in a transfer track or career-technical track program, whether the student had been dual-enrolled prior to college entry (i.e., took college courses as a high school student), and whether the student ever took a remedial course. All students were also required to indicate their degree and major intent upon college entry, which we combined into an educational intent variable with three categories: liberal arts and sciences (pursuing an associate or higher degree in fields such as social or natural science), occupational associate (pursuing an associate or higher

\footnotetext{
${ }^{2}$ The earnings record data are from Virginia, Maryland, New Jersey, Ohio, Pennsylvania, West Virginia, and the District of Columbia (DC).

${ }^{3}$ Students who entered for the first time in the summer and remained enrolled in the fall were included in the state's fall cohort dataset, but were coded in our models as entering in the summer.
} 
degree in an occupational field such as accounting or education), and occupational certificate (pursuing a certificate in an occupational field such as medical services or mechanics).

In terms of credentials obtained, VCCS offers both associate degrees and certificates. Following the Integrated Postsecondary Educational Data System (IPEDS) classification system, we divided certificates into short-term certificates (any non-degree credential officially awarded by the college which requires less than one year of full-time study) and long-term certificates (which require one or more years of full-time study). ${ }^{4}$ In addition to the credentials awarded by the VCCS colleges, students were also matched with National Student Clearinghouse (NSC) enrollment and graduation data, allowing us to track students even if they enrolled in or received credentials such as a bachelor's degree from colleges outside of the VCCS.

The UI data included quarterly earnings and industry of employment but provided no information on work hours or unemployment status. Quarters with missing earnings records were retained as missing rather than converted to zero earnings, based on two considerations. ${ }^{5}$ First, earnings gained through self-employment and government employment are not reported to the UI system; thus if a given student has missing earnings for a set of quarters, it is unclear whether they were unemployed during those quarters or working in a job that does not report to the UI system. Second, our primary research interest is exploring the influence of college attendance on student human capital accumulation; thus we are more interested in a student's earning potential across the given span of time rather than in whether the student was actually employed at a specific point in time.

We adjusted all quarterly earnings records to 2010 dollars to account for inflation. Given that the purpose of this study is to examine the earnings trajectories of different degree earners, we excluded individuals who had no UI records across all quarters; these individuals either did not enter the labor market at all or failed to be successfully matched with the UI database. We also excluded earnings records that were more than $\$ 100,000$ in a quarter; these outliers represented less than 0.01 percent of the sample but may have substantially influenced model estimates due to their extreme values. Finally, given that many individuals are inactive in the labor market when under age 18 years or above age 65, we discarded records for quarters in which a given individual was below 18 or over 65 . We did not, however, discard students who transferred to four-year colleges; by retaining these students in the sample, we were able to trace their earning trajectories during their enrollment period (i.e., both their community college and four-year enrollment) and, for those who eventually graduated with a bachelor's degree, during their post-award period. ${ }^{6}$ The final analysis sample included 847,420 quarterly earnings records across 67,735 students. $^{7}$

\footnotetext{
${ }^{4}$ Each state uses its own terminology when referring to non-degree awards of different lengths. In Virginia, career studies certificates refer to short-term certificates under our definition, and both certificates and diplomas refer to long-term certificates.

${ }^{5}$ Across all quarters in the sample, approximately 47 percent had missing earnings.

${ }^{6}$ Students still enrolled at the end of the observation period did not directly contribute to "post-enrollment" estimates, as they had no wage records for the "after college" time piece. However, these students still contributed to
} 


\subsection{Sample Description}

Table 1 presents summary demographic information, based on the highest award each student earned during the years under study: no credential, bachelor's degree, associate degree, long certificate, or short certificate.

Table 1. Descriptive Statistics for the Sample, by Highest Award

\begin{tabular}{|c|c|c|c|c|c|}
\hline & $\begin{array}{c}\text { No } \\
\text { Credential }\end{array}$ & $\begin{array}{l}\text { Bachel. } \\
\text { Degree }\end{array}$ & $\begin{array}{l}\text { Assoc. } \\
\text { Degree }\end{array}$ & $\begin{array}{l}\text { Long } \\
\text { Cert. }\end{array}$ & $\begin{array}{l}\text { Short } \\
\text { Cert. }\end{array}$ \\
\hline \multicolumn{6}{|l|}{ Demographic } \\
\hline Female (\%) & 53 & 57 & 60 & 62 & 54 \\
\hline Black (\%) & 25 & 11 & 14 & 19 & 28 \\
\hline Hispanic (\%) & 6 & 6 & 6 & 6 & 3 \\
\hline White (\%) & 60 & 71 & 70 & 68 & 65 \\
\hline Other race/ethnicity (\%) & 3 & 5 & 3 & 3 & 2 \\
\hline Age at college entry (years) & 22 & 20 & 21 & 22 & 26 \\
\hline \multicolumn{6}{|l|}{ Academic (\%) } \\
\hline Transfer track (vs. career-technical) & 56 & 79 & 63 & 50 & 24 \\
\hline Dual-enrolled prior to entry & 12 & 27 & 22 & 21 & 16 \\
\hline Federal financial aid eligibility & 42 & 32 & 41 & 49 & 49 \\
\hline Intent: liberal arts and sciences & 46 & 65 & 52 & 42 & 20 \\
\hline Intent: occupational associate & 37 & 30 & 38 & 25 & 22 \\
\hline Intent: occupational short cert. & 17 & 5 & 10 & 34 & 57 \\
\hline Took remedial courses & 60 & 41 & 55 & 60 & 45 \\
\hline \multicolumn{6}{|l|}{ Cohort (\%) } \\
\hline Cohort 2006-2007 & 31 & 47 & 32 & 28 & 27 \\
\hline Cohort 2007-2008 & 34 & 37 & 34 & 33 & 35 \\
\hline Cohort 2008-2009 & 35 & 17 & 34 & 39 & 37 \\
\hline Observations & 47,124 & 6,068 & 11,107 & 1,906 & 1,530 \\
\hline
\end{tabular}

Note. This table is based on first-time students who enrolled in the Virginia Community College System during the 2006-2007, 2007-2008, and 2008-2009 years that matched with at least some UI records.

the pre-college and during-college growth trajectory estimates. In a separate robustness check, we excluded students who were still enrolled in college at the end of the observation period, and the patterns of results remained fairly similar.

${ }^{7}$ In a separate robustness check, we further limited the sample to individuals who worked before college enrollment, and the results were not qualitatively different. 
Among 67,735 students, the majority $(N=47,124)$ did not earn any credential; they had either dropped out or were still enrolled by the spring of 2013. Approximately 16 percent $(N=$ $11,017)$ earned an associate degree as their highest award, followed by 9 percent $(N=6,068)$ who earned a bachelor's degree. Relatively few students earned non-degree awards as their highest credential: only 1,906 earned long-term and 1,530 earned short-term certificates.

Overall, the award groups appeared to differ substantially in terms of their demographic makeup; for example, compared with the other four groups, bachelor's degree earners seemed younger at entry, less likely to be eligible for financial aid, less likely to take remedial coursework, and as would be expected, more likely to be formally on a "transfer track" and to enter with an intent to major in the liberal arts and sciences. Table 1 also shows that earlier cohorts had higher graduation rates, due to the longer tracking timeframe available; for example, nearly half of bachelor degree earners entered in fall 2006, while only about one-sixth entered in fall 2008.

Table 2 displays quarterly average earnings for each award group during each student's pre-enrollment, during-enrollment, and post-exit periods.

Table 2. Descriptive Statistics for Quarterly Earnings (in 2010 Dollars) Across Time, by Degree Award

\begin{tabular}{lcccc}
\hline \hline & Prior to College & During College & After College & Overall \\
\hline No award & 4,067 & 3,755 & 5,169 & 4,384 \\
& $(\mathrm{~N}=95,271)$ & $(\mathrm{N}=251,700)$ & $(\mathrm{N}=239,836)$ & $(\mathrm{N}=586,807)$ \\
Bachelor’s & 2,828 & 2,926 & 6,306 & 3,531 \\
& $(\mathrm{~N}=6,123)$ & $(\mathrm{N}=52,694)$ & $(\mathrm{N}=13,030)$ & $(\mathrm{N}=71,847)$ \\
Associate & 3,780 & 3,579 & 6,172 & 4,088 \\
& $(\mathrm{~N}=16,972)$ & $(\mathrm{N}=98,793)$ & $(\mathrm{N}=26,668)$ & $(\mathrm{N}=142,433)$ \\
Long cert. & 3,584 & 3,279 & 5,474 & 3,865 \\
& $(\mathrm{~N}=3,396)$ & $(\mathrm{N}=14,674)$ & $(\mathrm{N}=5,942)$ & $(\mathrm{N}=24,012)$ \\
Short cert. & 5,262 & 4,704 & 6,328 & 5,384 \\
& $(\mathrm{~N}=4,643)$ & $(\mathrm{N}=9,928)$ & $(\mathrm{N}=7,750)$ & $(\mathrm{N}=22,321)$ \\
Overall & 3,999 & 3,618 & 5,348 & 4,273 \\
& $(\mathrm{~N}=126,405)$ & $(\mathrm{N}=427,789)$ & $(\mathrm{N}=293,226)$ & $(\mathrm{N}=847,420)$ \\
\hline \hline
\end{tabular}

Among students who exited college, the length of the post-exit period varied from 1 to 28 quarters, with a median of 15 quarters (approximately 3.5 years) and an interquartile range of 10 . The first column suggests that students who would eventually earn different types of awards already differed sharply in their earnings during the pre-enrollment period; for example, eventual short-term certificate awardees were earning nearly twice as much as eventual bachelor's degree awardees. The final row shows that, overall, students’ earnings dropped slightly during 
enrollment (reflecting the opportunity costs of college attendance), but jumped dramatically after their exit from college. This pattern seemed relatively consistent across awardee groups, with the exception of bachelor's degree earners, who did not seem to suffer a during-enrollment earnings drop.

\section{Analysis}

To explore the earnings trajectories of different award groups, we first expanded Equation 4 to include key time-varying controls as well as student-level predictors, as shown in Equation $5:^{8}$

$$
\begin{aligned}
& Y_{i j}=\beta_{00}+\beta_{01} \text { Award }_{j}+\beta_{02} X_{j}+\beta_{10} \text { Time }_{i j}+\beta_{11} \text { Time }_{i j} \times \text { Award }_{j}+\beta_{12} \text { Time }_{i j} \times X_{j} \\
& +A_{i j}+\varepsilon_{0 j}+\varepsilon_{1 j}+\mu_{i j}
\end{aligned}
$$

This "one-piece" GCM includes a vector of dichotomous indicators for the highest education award obtained $\left(\right.$ Award $\left._{j}\right)$; the vector of student characteristics listed in Table $1\left(\mathrm{X}_{j}\right)$, each of which was centered at the sample mean; and dichotomous indicators for the two quarters prior to college entry $\left(A_{i j}\right)$, allowing these time points to vary from the student's overall trend in order to control for Ashenfelter dip. Time is coded as the time lapse between the given $i j$ and the student's quarter of leaving college; for example, -0.25 would represent the quarter prior to exit and +1.0 would represent four quarters post-exit. Thus $\beta_{00}$ represents the average earnings of non-awardees upon college exit. In Equation 5, the coefficients for the Award variables are minimally informative: they indicate the extent to which different award groups have different levels of earnings at college exit $\left(\beta_{01}\right)$, and whether different award groups have different slopes of growth in earnings across the entire time period under examination $\left(\beta_{11}\right)$.

We then expanded to a two-piece GCM that allows individuals' trajectories to differ between the period prior to college exit (i.e., the combined pre-enrollment and during-enrollment periods) and the post-exit period: ${ }^{9}$

\footnotetext{
${ }^{8}$ As a sensitivity check, we also ran Equations 5, 6, and 7 using logged earnings rather than their natural scale to capture nonlinearity and found very similar results.

${ }^{9}$ Non-awardees still enrolled at the end of the tracking period remained included in the sample and contributed to the pre-exit coefficients; for these students, $\beta_{00}$ represents estimated earnings at the last time point at which each student was tracked.
} 


$$
\begin{aligned}
& Y_{i j}=\beta_{00}+\beta_{01} \text { Award }_{j}+\beta_{02} X_{j}+\beta_{10} \text { Time }_{i j}+\beta_{11} \text { Time }_{i j} \times \text { Award }_{j}+\beta_{12} \text { Time }_{i j} \times X_{j} \\
& +\gamma_{01} P_{i j}+\gamma_{02} P_{i j} \times \text { Award }_{j}+\gamma_{03} P_{i j} \times X_{j}+\gamma_{10} P_{i j} \times \text { Time }_{i j}+\gamma_{11} P_{i j} \times \text { Time }_{i j} \times \text { Award }_{j} \\
& +\gamma_{12} P_{i j} \times \text { Time }_{i j} \times X_{j}+A_{i j}+\varepsilon_{\beta 0 j}+\varepsilon_{\beta 1 j}+\varepsilon_{\mathrm{P} 0 j}+\varepsilon_{\mathrm{P} 1 j}+\mu_{i j}
\end{aligned}
$$

Equation 6 introduces a new parameter $P_{i j}$, which is equal to 1 in quarters after college exit. The inclusion of $P_{i j}$ and its interactions with time and award slightly alters the interpretation of $\beta_{00}$, which now represents the model-adjusted prediction of the average quarterly earnings of non-awardees upon college exit, based on the growth curve profile prior to college exit. Accordingly, $\beta_{00}$ is most easily interpreted as non-awardees' estimated earnings immediately prior to college exit (hereafter referred to as "immediate pre-exit earnings"). The vector $\beta_{01}$ tests the variation in this intercept across the award groups. The new parameter $\gamma_{01}$ estimates the difference between immediate pre-exit earnings and the model-adjusted prediction of the average quarterly earnings of non-awardees upon college exit, based on the growth curve profile subsequent to college exit (hereafter referred to as "immediate post-exit earnings"). ${ }^{10}$ The vector $\gamma_{02}$ tests the variation in the extent of this pre-post difference between award groups. Thus $\gamma_{02}$ is conceptually similar to a difference-in-differences estimator, although it tests for variation across groups in terms of the immediate difference in earnings due to exiting college, while a typical difference-in-differences estimator would test for variation across groups in terms of the average difference in earnings from pre- to post-exit.

The unique contribution of the growth curve model over the difference-in-differences and individual fixed-effects models becomes apparent when we consider the remaining parameters in the model. With the inclusion of the $\mathrm{P}_{i j}$ terms, the coefficient $\beta_{10}$ now represents the overall slope, or growth rate of the no-credential group prior to college exit; the vector $\beta_{11}$ explores whether pre-exit growth rates vary by different award groups; $\gamma_{10}$ represents the overall slope differential between pre-exit and post-exit within the no-credential group (i.e., the extent to which an individual's growth rate inflects upward or downward at the point of college exit); and the vector $\gamma_{11}$ tests for variation in this slope differential across award groups.

Similar to an individual fixed-effects approach, Equation 6 assumes that a given individual follows one general trajectory across the pre-enrollment and during-enrollment period (although the individual fixed-effects model may allow for some deviations from this single trajectory based on Ashenfelter dip indicators, quarterly fixed effects, an indicator for current enrollment, and so on). While enrolled in college, however, students are subject to a new mix of human capital accrual: they are likely to accrue less work experience over this time period, while at the same time accruing knowledge through their coursework that may be applicable to their work duties. If this new mix of human capital accrual alters not just the level but also the slope of

\footnotetext{
${ }^{10}$ Immediate post-exit earnings represents a student's estimated earnings if he or she were to be employed immediately upon exit; because this estimate is based on the overall post-exit growth curve rather than solely on data from the quarter of exit, the model does not require the student to actually be employed at this time point.
} 
earnings, then it would be more appropriate to allow for an entirely new trajectory of earnings during this phase of time. Thus we further extend the two-piece GCM into a three-piece GCM by dividing $P_{i j}$ into two dummies: $\mathrm{P}_{1 i j}$, which is equal to 1 in quarters between college entry and college exit, and $P_{2 i j}$, which is equal to 1 in quarters after college exit. Thus under the three-piece GCM, each individual has three wage growth profiles: before college entry, during college enrollment, and after college exit.

$$
\begin{aligned}
& Y_{i j}=\beta_{00}+\beta_{01} \text { Award }_{j}+\beta_{02} X_{j}+\beta_{10} \text { Time }_{i j}+\beta_{11} \text { Time }_{i j} \times \text { Award }_{j}+\beta_{12} \text { Time }_{i j} \times X_{j} \\
& +\gamma_{01} P_{1 i j}+\gamma_{02} P_{1 i j} \times \text { Award }_{j}+\gamma_{03} P_{1 i j} \times X_{j}+\gamma_{10} P_{1 i j} \times \text { Time }_{i j}+\gamma_{11} P_{1 i j} \times \text { Time }_{i j} \times \text { Award }_{j}+ \\
& \gamma_{12} P_{1 i j} \times \text { Time }_{i j} \times X_{j}+\gamma_{21} P_{2 i j}+\gamma_{22} P_{2 i j} \times \text { Award }_{j}+\gamma_{23} P_{2 i j} \times X_{j}+\gamma_{30} P_{2 i j} \times \text { Time }_{i j}+ \\
& \gamma_{31} P_{2 i j} \times \text { Time }_{i j} \times \text { Award }_{j}+\gamma_{32} P_{2 i j} \times \text { Time }_{i j} \times X_{j}+A_{i j}+\varepsilon_{\beta 0 j}+\varepsilon_{\beta 1 j}+\varepsilon_{\mathrm{P} 0 j}+\varepsilon_{\mathrm{P} 1 j}+\varepsilon_{\mathrm{P} 2 j}+ \\
& \varepsilon_{\mathrm{P} 3 j}+\mu_{i j}
\end{aligned}
$$

The inclusion of the additional $P_{i j}$ dummy results in a further shift of the interpretation of $\beta_{00}$; the term now represents non-awardees' immediate pre-exit earnings based on the growth curve profile prior to college entry - that is, the student's estimated earnings at his or her time point of actual exit, based on the counterfactual that the student never attended college at all. This specification assumes that in the absence of college attendance, the student's earnings would have continued to grow at the same rate observed prior to college entry. Hereafter we refer to this estimate as the "non-college earnings level." The first additional intercept $\gamma_{01}$ tests the difference between non-awardees' non-college earnings level and their estimated immediate pre-exit earnings based on the growth curve profile during college enrollment (we continue to refer to the latter estimate as "immediate pre-exit earnings"). In essence, $\gamma_{01}$ tests whether college enrollment has altered a non-awardee's estimated level of earnings by the time point of his or her actual exit from college. The second additional intercept $\gamma_{21}$ tests the difference between nonawardees' non-college earnings level and their immediate post-exit earnings; thus for nonawardees, $\gamma_{21}$ represents the immediate labor market returns to college enrollment, while the $P_{2 i j}$ interactions with Award test for variation across award groups in terms of immediate returns.

In terms of the slope coefficients, $\beta_{10}$ estimates non-awardees' earnings growth in the absence of college (the "non-college rate of earnings growth"), while its interactions with Award test for variation in this rate of growth across types of awards. The term $\gamma_{10}$ tests for a difference between non-awardees' non-college rate of earnings growth and the rate of growth based on during-enrollment data. That is, it tests whether college enrollment altered the student's initial earnings trajectory, while the $P_{1 i j}$ interactions with Time and Award test for variations in the extent of this trajectory differential across award groups. The term $\gamma_{30}$ tests for a difference between non-awardees' non-college rate of earnings growth and their post-exit growth, representing the labor market returns to education in terms of an increased rate of earnings 
growth across time, while the $P_{2 i j}$ interactions with Time and Award test for variation across award groups in this increase.

It is possible to further expand the model by including other characteristics of time (e.g., a quadratic term or quarterly fixed effects) within each of the three time periods. In our dataset, however, trends within each time piece were fairly linear. Therefore, to help the reader clearly understand the results from this novel approach to investigating community college labor market returns, we elected to keep the model relatively simple and parsimonious. In order to examine how well our functional form for growth fit the data, we calculated the proportion of withinperson variance (unconditional $\mu_{i j}$ ) explained by each model's level-1 growth parameters (Raudenbush \& Bryk, 2002). Overall, the one-piece model's growth parameters explained 35 percent of the within-person variance, while both the two-piece and three-piece models' growth parameters explained 36 percent of the within-person variance. Thus the addition of the various $P_{i j}$ terms and their interactions with Time did not particularly improve the functional form for growth; however, as the inclusion of these terms allowed us to examine much more interesting and useful hypotheses, we retained these terms in the model. In contrast, the inclusion of more complex functional forms (such as quadratic terms) tended to increase model complexity and hinder clear interpretation of the results, without substantially improving the model's functional form.

To further explore our main results, we also employed two types of supplemental models. First, we examined the extent to which labor market returns are due to accrued credits versus awards by including total college-level credits earned by each student in the three-piece GCM model, resulting in a “sheepskin” model that estimates the change in students' earnings trajectories based on the award alone. Second, we ran the three-piece GCM separately for key student characteristics, including gender, age (older versus younger than 25 at college entry), and field of study (humanities and social science, math and science, health, mechanics and construction, public administration, business, and education).

\section{Results}

\subsection{Primary Models}

Table 3 presents the estimates for the growth and award parameters based on the twoand three-piece GCM models. We first discuss the results for the two-piece model, and then contrast it with the results for the three-piece model. Figure 1 portrays the results of the threepiece model in graphic form. ${ }^{11}$

\footnotetext{
${ }^{11}$ Note that, due to wide variation between students in terms of the number of quarters included in each of the three pieces of time, it is not possible to include all three pieces on the same $x$-axis of Time; we can include only up to two pieces on the same $x$-axis while accurately portraying both the intercepts and slopes for each piece. Due to more
} 
Table 3. Estimates for the Piecewise Linear Growth Curve Model (in 2010 Dollars)

\begin{tabular}{|c|c|c|c|}
\hline & $\begin{array}{c}\text { (1) } \\
\text { Two-Piece GCM }\end{array}$ & $\begin{array}{c}\text { (2) } \\
\text { Three-Piece GCM } \\
\end{array}$ & $\begin{array}{c}\text { (3) } \\
\text { Sheepskin Effects }\end{array}$ \\
\hline Intercept & $3,477(15)^{* * *}$ & $3,277(22)^{* * *}$ & $3,209(22)^{* * *}$ \\
\hline Bachelor's (BA) & $-375(47) * * *$ & $486(140)^{* * *}$ & $362(140)^{* * *}$ \\
\hline Associate (AA) & $255(35) * * *$ & $565(72)^{* * *}$ & $426(73)^{* * *}$ \\
\hline Long cert. (LC) & $-66(77)$ & $122(143)$ & 43 (143) \\
\hline Short cert. (SC) & $352(85)^{* * *}$ & $338(118)^{* * *}$ & $301(118)^{* *}$ \\
\hline During college & & $162(19)^{* * *}$ & $140(19)^{* * *}$ \\
\hline During $\times$ BA & & $-847(133)^{* * *}$ & $-935(133)^{* * *}$ \\
\hline During $\times$ AA & & $-318(65)^{* * *}$ & $-423(66)^{* * *}$ \\
\hline During $\times$ LC & & $-213(127)^{*}$ & $-303(127)^{* *}$ \\
\hline During $\times$ SC & & $-2(96)$ & $-36(96)$ \\
\hline After college & $115(11)^{* * *}$ & $284(18)^{* * *}$ & $257(18)^{* * *}$ \\
\hline After $\times$ BA & $1,156(40)^{* * *}$ & $333(138)^{* *}$ & $290(138)^{* *}$ \\
\hline After $\times$ AA & $437(30)^{* * *}$ & $152(69) * *$ & $13(70)$ \\
\hline After $\times$ LC & $505(64) * * *$ & $339(135)^{* *}$ & 219 (135) \\
\hline After $\times$ SC & $80(58)$ & $112(98)$ & $57(98)$ \\
\hline Time (T) & $70(1)^{* * *}$ & $67(1)^{* * *}$ & $64(1)^{* * *}$ \\
\hline $\mathrm{T} \times \mathrm{BA}$ & $-25(3) * * *$ & $11(7)$ & $6(7)$ \\
\hline $\mathrm{T} \times \mathrm{AA}$ & $-1(2)$ & $14(4)^{* * *}$ & $8(4)^{* *}$ \\
\hline $\mathrm{T} \times \mathrm{LC}$ & $-1(5)$ & $9(8)$ & $6(8)$ \\
\hline $\mathrm{T} \times \mathrm{SC}$ & $12(5)^{* *}$ & $12(7)$ & $10(7)$ \\
\hline During $\times \mathrm{T}$ & & $-12(1) * * *$ & $-13(1)^{* * *}$ \\
\hline During $\times \mathrm{T} \times \mathrm{BA}$ & & $-21(6)^{* * *}$ & $-25(6)^{* * *}$ \\
\hline During $\times \mathrm{T} \times \mathrm{AA}$ & & $-7(3)^{* *}$ & $-12(3) * * *$ \\
\hline During $\times \mathrm{T} \times \mathrm{LC}$ & & $-5(7)$ & $-10(7)$ \\
\hline During $\times \mathrm{T} \times \mathrm{SC}$ & & $3(6)$ & $1(6)$ \\
\hline After $\times \mathrm{T}$ & $23(2) * * *$ & $27(2) * * *$ & $30(2)^{* * *}$ \\
\hline After $\times \mathrm{T} \times \mathrm{BA}$ & $366(9)^{* * *}$ & $328(11)^{* * *}$ & $333(11)^{* * *}$ \\
\hline After $\times \mathrm{T} \times \mathrm{AA}$ & $145(5)^{* * *}$ & $129(6)^{* * *}$ & $133(6)^{* * *}$ \\
\hline After $\times \mathrm{T} \times \mathrm{LC}$ & $86(10)^{* * *}$ & $74(12)^{* * *}$ & $77(12)^{* * *}$ \\
\hline After $\times \mathrm{T} \times \mathrm{SC}$ & $4(8)$ & $5(10)$ & $5(10)$ \\
\hline $\begin{array}{l}\text { Total college-level } \\
\text { Credits completed }\end{array}$ & & & $5(0) * * *$ \\
\hline Observations & 847,420 & 847,420 & 847,420 \\
\hline
\end{tabular}

Note. Coefficients in column (1) are based on Equation 6; those in column (2) are based on Equation 7; those in column (3) are also based on Equation 7 but further control for total number of college-level credits completed. Standard errors are in parentheses.

${ }^{* * *} p<.01,{ }^{* *} p<.05, * p<.1$.

modest variation between award groups during college, we have chosen to show the non-college and post-exit pieces in panel A (which also provides an intuitive graphical representation of the key returns-to-award coefficients), while panel B shows the during-enrollment piece on a magnified $y$-axis for Earnings. 


\section{Figure 1. Estimated Linear Growth Curves of Quarterly Earnings, Based on the Three-Piece Growth Curve Model}
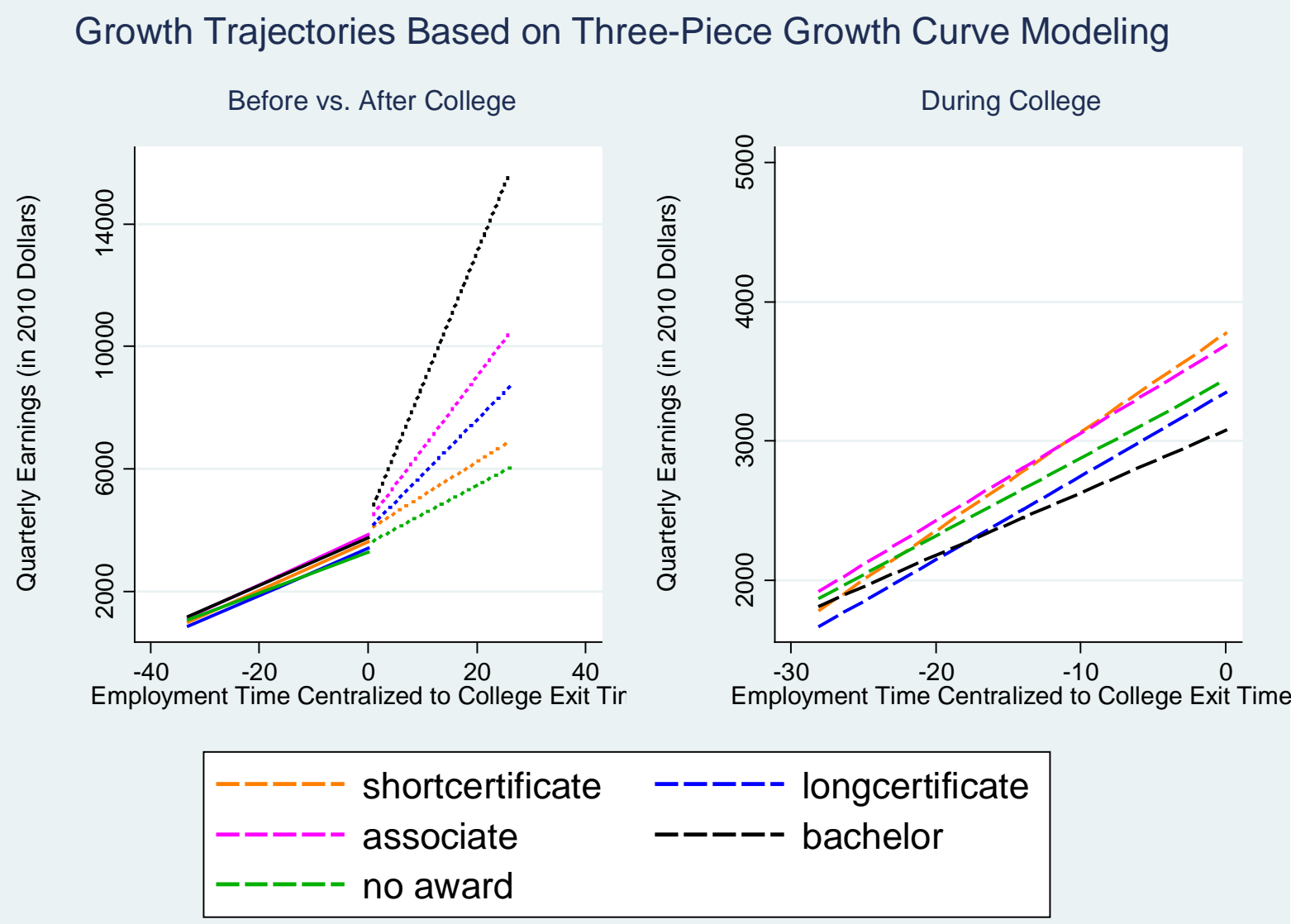

Note. This figure presentss the results of the three-piece model (Equation 7) in graphic form. Time is centered at college exit for each student. Note that, due to wide variation between students in terms of the number of quarters included in each of the three pieces of time, it is not possible to include all three pieces on the same $x$-axis of Time; we can include up to only two pieces on the same $x$-axis while accurately portraying both the intercepts and slopes for each piece. Due to more modest variation between award groups during college, we have chosen to show the non-college and post-exit pieces in panel A, while panel B shows the during-enrollment piece on using a magnified $y$-axis scale for Earnings.

In Table 3, the Intercept row for the two-piece model indicates non-awardees' immediate pre-exit earnings level $(\$ 3,477)$, while the BA, AA, LC, and SC coefficients indicate variation in these pre-exit earnings based on eventual award level; for example, short certificate awardees already had stronger earnings than non-awardees just prior to exit (an additional \$352 in the quarter). The After College coefficient indicates the immediate jump in earnings among nonawardees when they exit college. Non-awardees experienced only a small jump upon exit (\$115), which may reflect an increase in their work hours, while awardees (with the exception of short certificate awardees) experienced substantially stronger jumps. The overall coefficient for Time in the two-piece model indicates the growth in earnings among non-awardees across the entire pre-exit period (including both pre- and during-enrollment). Non-awardees' earnings increased 
by approximately $\$ 70$ per quarter during this period, associate and long certificate awardees experienced similar growth, and short certificate awardees experienced slightly stronger growth. In contrast, bachelor's degree awardees experienced lesser growth across the pre-exit period (\$70 - \$25, or \$45 per quarter). The interaction between After College and Time indicates that non-awardees' earnings growth increased by an additional \$23 upon college exit, resulting in a new growth rate of $\$ 70+\$ 23$, or $\$ 93$ per quarter. Short certificate earners experienced a similarly modest upward inflection, which was dwarfed by much stronger inflections among bachelor's, associate, and long-certificate awardees; for example, the earnings rate of bachelor's degree awardees increased by $\$ 389$ (\$23 + \$366) upon college exit, for a new growth rate of \$434 per quarter.

It may seem odd that the two-piece model finds an overall growth in quarterly wages across the pre-exit period, given that the descriptive data in Table 2 shows a depression in students' earnings during the enrollment period. Yet after taking into account a general depression in earnings level upon entry, students' earnings could certainly grow across the enrollment period, due to ongoing human capital accrual. The three-piece model helps us more clearly delineate this contrasting pattern of depression and growth.

The overall Intercept for the three-piece model indicates the estimated non-college earnings level among non-awardees at the time of actual college exit (\$3,277 in the quarter), while the BA, AA, LC, and SC coefficients indicate variation in estimated non-college earnings level; for example, short certificate awardees were estimated to have much stronger earnings levels than non-awardees (an additional \$338 in the quarter), even had they never attended college. The During College coefficients estimate how college attendance altered students' earnings levels prior to exit. While current college attendance increased the earning levels of non-awardees (by \$162) and short certificate awardees (by \$162 - \$2, or \$160) it depressed awardees’ earnings. In particular example, eventual bachelor’s degree awardees earned substantially less during enrollment than they would have in the absence of college (\$162 $\$ 847$, or $\$ 685$ less). These results suggest that in comparison with eventual earners of longer term awards, non-awardees and short certificate awardees remained more strongly attached to the labor market during enrollment. The After College coefficients indicate the immediate postexit returns to college education, compared with estimated non-college earnings levels. Nonawardees received a significant immediate return (\$284), which was similar to that of short certificate awardees; in contrast, immediate returns were significantly stronger for longer term credentials. For example, long certificate awardees experienced immediate returns of \$623 in the quarter (\$284 + \$339).

The coefficients for Time in the three-piece model reflect the estimated rate of noncollege earnings growth. Non-awardees’ non-college growth was estimated at \$67 per quarter; most eventual awardees experienced similar growth, although long certificate awardees’ growth was slightly stronger ( $\$ 67+\$ 14$, or $\$ 81$ per quarter). The interactions between During College and Time reflect the estimated impact of current college enrollment on students' earnings trajectories. Across all groups, current college attendance significantly flattened students' 
trajectories of earnings growth, although the overall rate of during-college growth was still positive for all groups. During-college growth was strongest among eventual short certificate awardees ( $\$ 67+\$ 12-\$ 12+\$ 3$, or $\$ 70$ per quarter), and most modest among eventual bachelor's degree awardees ( $\$ 67+\$ 11-\$ 12-\$ 21$, or $\$ 45$ per quarter). Finally, the interactions between After College and Time reflect the differential between students’ estimated non-college growth and estimated post-exit growth, or the returns to education in terms of earnings growth over time. Earnings growth increased only modestly due to college exit among non-awardees (\$27 per quarter) and short certificate awardees $(\$ 27+\$ 5)$, while the other award groups experienced much stronger increases in growth. For example, associate degree awardees’ growth rate increased by an estimated $\$ 156$ per quarter $(\$ 27+\$ 129)$, resulting in a new growth rate of $\$ 237$ per quarter $(\$ 67+\$ 14+\$ 27+\$ 129)$.

Overall, in comparison with non-awardees, the three-piece model suggests that only short certificates did not provide awardees with significantly stronger returns to education, both in terms of immediate returns and stronger growth in earnings across time. Moreover, the longerterm the credential, the stronger seemed the upward inflection in post-exit earnings growth across time.

\subsection{Comparing the Two-Piece and Three-Piece GCM Results}

Overall, the two- and three-piece models yield very similar estimates for each group's post-exit trajectories, as shown in Table 4. Immediately post-exit, non-awardees were earning approximately $\$ 3,600$, short and long certificate awardees were earning roughly $\$ 450$ more than non-awardees, and associate and bachelor's degree awardees were earning yet another \$250 to \$350 more than short and long certificate awardees. More strikingly, after exiting college, nonawardees and short certificate awardees experienced only a modest growth in earnings (approximately \$100 per quarter), while long certificate earners had slightly stronger growth, associate degree earners had even stronger growth, and bachelor's degree earners had the strongest growth (over \$400 per quarter). 
Table 4. Intercepts and Slopes Based on Estimates From the Piecewise Growth Curve Model (in 2010 Dollars)

\begin{tabular}{|c|c|c|c|c|c|c|}
\hline & \multicolumn{3}{|c|}{ Intercept } & \multicolumn{3}{|c|}{ Slope } \\
\hline & Before & During & After & Before & During & After \\
\hline \multicolumn{7}{|c|}{ Two-piece model (Before \& During vs. After, with time centered at college exit) } \\
\hline No award & 3,477 & & 3,592 & 70 & & 94 \\
\hline Bachelor's & 3,103 & & 4,374 & 45 & & 435 \\
\hline Associate & 3,733 & & 4,285 & 69 & & 237 \\
\hline Long cert. & 3,412 & & 4,032 & 69 & & 178 \\
\hline Short cert. & 3,830 & & 4,025 & 82 & & 110 \\
\hline \multicolumn{7}{|c|}{ Three-piece model (Before vs. During vs. After, with time centered at college exit) } \\
\hline No award & 3,277 & 3,440 & 3,561 & 67 & 56 & 95 \\
\hline Bachelor's & 3,763 & 3,078 & 4,379 & 78 & 45 & 434 \\
\hline Associate & 3,842 & 3,687 & 4,278 & 81 & 63 & 237 \\
\hline Long cert. & 3,399 & 3,349 & 4,022 & 77 & 60 & 179 \\
\hline Short cert. & 3,615 & 3,775 & 4,011 & 79 & 71 & 111 \\
\hline
\end{tabular}

Note. This table presents intercepts and slopes for each degree group calculated based on the two-piece and threepiece growth curve models. As time is centered at college exit, the intercepts represent the predicted quarterly earnings by degree group upon college exit, based on student earnings growth profiles before college enrollment, during college enrollment (only for the three-piece model), and after college exit. The slopes represent the predicted earnings growth rate in each period of time by degree group.

While the two models agree on their description of students’ post-exit trajectories, they differ in their estimates of the extent to which these trajectories were affected by community college awards, largely because the two models differ in their counterfactual. Similar to a difference-in-differences or individual fixed-effects model, the two-piece specification assumes that the student's earnings across both the pre-enrollment and during-enrollment periods represent the appropriate counterfactual, while the three-piece specification assumes that the earnings that the student would have had in the absence of college attendance represent the appropriate counterfactual. The latter choice results in milder estimates for immediate postaward bumps as well as in post-award earnings accelerations for each award group. ${ }^{12}$

\footnotetext{
${ }^{12}$ In order to maintain consistency between the two-piece and three-piece model, our two-piece model did not include explicit indicators for college attendance as an individual fixed-effects model would; however, a robustness check indicated that while inclusion of enrollment controls in the two-piece model attenuated its estimates slightly, they still remained larger than the estimates from the three-piece model.
} 


\subsection{Supplemental Analyses}

In the three-piece GCM, estimated returns to community college awards include the effects of both the award itself, and of the knowledge accrued through the college-level coursework that led to the award. The finding that non-awardees experience an immediate postexit earnings bump but no increase in earnings growth may suggest that the knowledge they accrue through coursework provides some immediate benefits in terms of earnings-but without formal certification of that knowledge by the college, employers are unlikely to reward the student with an acceleration in earnings growth over time. To further investigate this notion, the final column of Table 3 shows the results for a "sheepskin effects" model, which removes the effect of college-level credit accrual from the award coefficients. Removing the effect of credit accrual seems to decrease immediate post-exit returns among all award earners; however, increases in post-exit earnings growth remain broadly similar. These results tend to reinforce the notion that formal certification of knowledge is required in order to increase earnings growth across time.

To explore variation in our results across key student characteristics, Tables 5 and 6 display the three-piece GCM results separately for male versus female students, older versus younger students, and students pursuing different fields of study. The contrasts between male and female students in terms of immediate post-exit returns appear to be quite consistent with results from other studies of community college credentials: compared with men, women seemed to experience stronger returns to degrees and weaker returns to certificates. Much of this difference may be explained by the different fields of study chosen by men versus women, as is discussed in more detail in Liu et al. (2015) and Dadgar and Weiss (2014). In terms of increases in post-exit growth rates, men seemed to experience somewhat stronger increases than women within most award groups; for example, among bachelor's degree awardees, men’s increase in growth was estimated at $\$ 395$ per quarter $(\$ 50+\$ 345)$ compared with $\$ 341$ for women $(\$ 12+$ \$329). However, among associate degree awardees, men’s and women’s increase in growth rates appeared fairly similar (\$165 for women and \$151 for men).

Comparing the results for older versus younger students, we found several striking differences. First, prior to enrollment, older students earned higher salaries and also experienced stronger growth in earnings across time. During enrollment, older students bore the brunt of the overall sample's drop in earnings and deceleration in earnings growth. Post-exit, older students also experienced a dip in earnings (the "reverse Ashenfelter dip" identified by Jacobson et al., 2005). Older students who failed to earn an award or who earned a short certificate seemed unlikely to recover from the dip over time (given that their estimated growth in earnings was negative or null); the model forecasted that older long certificate awardees would overcome the dip in approximately 1.5 years and associate degree awardees in well under a year, but bachelor's degree awardees might require up to five years. (This latter estimate should be interpreted cautiously, however, as our follow-up timeframe was not long enough to capture five years post-exit for bachelor's degree earners.) 
Table 5. Estimates for the Three Piece Growth Curve Model by Gender and Age (in 2010 Dollars)

\begin{tabular}{|c|c|c|c|c|}
\hline & \multicolumn{2}{|c|}{ By Gender } & \multicolumn{2}{|c|}{ By Age } \\
\hline & Female & Male & Older $(\geq 25)$ & Younger $(<25)$ \\
\hline Intercept & $3,100(28) * * *$ & $3,379(36) * * *$ & $6,300(152)^{* * *}$ & $3,733(32)^{* * *}$ \\
\hline Bachelor’s (BA) & $160(166)$ & $548(240)^{* *}$ & $2,461(553)^{* * *}$ & $108(136)$ \\
\hline Associate (AA) & $354(85)^{* * *}$ & $545(129)^{* * *}$ & 95 (198) & $612(76)^{* * *}$ \\
\hline Long cert. (LC) & $347(169)^{* *}$ & $-434(248)^{*}$ & $-616(347)^{*}$ & $482(159)^{* * *}$ \\
\hline Short cert. (SC) & $-106(162)$ & $430(178)^{* *}$ & $-76(242)$ & $425(148)^{* * *}$ \\
\hline During college & $142(24)^{* * *}$ & $124(30)^{* * *}$ & $-435(106)^{* * *}$ & $-163(26)^{* * *}$ \\
\hline During $\times$ BA & $-595(158)^{* * *}$ & $-1,365(229)^{* * *}$ & $-2,011(495)^{* * *}$ & $-660(130)^{* * *}$ \\
\hline During $\times$ AA & $-411(76)^{* * *}$ & $-437(117)^{* * *}$ & $-590(163)^{* * *}$ & $-498(70)^{* * *}$ \\
\hline During $\times$ LC & $-537(151)^{* * *}$ & $7(221)$ & $-782(279)^{* * *}$ & $-396(145)^{* * *}$ \\
\hline During $\times$ SC & $-143(136)$ & $121(141)$ & $-538(174)^{* * *}$ & $150(127)$ \\
\hline After college & $206(24) * * *$ & $315(30)^{* * *}$ & $-197(96)^{* *}$ & $-68(26)^{* * *}$ \\
\hline After $\times$ BA & $588(164)^{* * *}$ & $-77(237)$ & $-1,655(532) * * *$ & $649(134)^{* * *}$ \\
\hline After $\times$ AA & $135(81)^{*}$ & $-154(125)$ & $-17(176)$ & $-63(75)$ \\
\hline After $\times$ LC & $-56(160)$ & $617(233)^{* * *}$ & $-175(291)$ & 189 (154) \\
\hline After $\times$ SC & $-54(142)$ & 225 (142) & $-291(171)^{*}$ & $301(133)^{* *}$ \\
\hline Time (T) & $62(2) * * *$ & $64(2)^{* * *}$ & $105(8)^{* * *}$ & $64(2) * * *$ \\
\hline $\mathrm{T} \times \mathrm{BA}$ & $2(8)$ & $11(12)$ & $81(24)^{* * *}$ & $-5(7)$ \\
\hline $\mathrm{T} \times \mathrm{AA}$ & $7(4)^{*}$ & $10(7)$ & $-5(10)$ & $17(4)^{* * *}$ \\
\hline $\mathrm{T} \times \mathrm{LC}$ & $17(9)^{*}$ & $-10(14)$ & $-8(19)$ & $20(9)^{* *}$ \\
\hline $\mathrm{T} \times \mathrm{SC}$ & $6(9)$ & $6(12)$ & $9(14)$ & $15(9)$ \\
\hline During $\times \mathrm{T}$ & $-15(1)^{* * *}$ & $-11(2)^{* * *}$ & $-37(7) * * *$ & $-29(2) * * *$ \\
\hline During $\times \mathrm{T} \times \mathrm{BA}$ & $-8(8)$ & $-47(11)^{* * *}$ & $-71(22)^{* * *}$ & $-11(6)^{*}$ \\
\hline During $\times \mathrm{T} \times \mathrm{AA}$ & $-12(4)^{* * *}$ & $-13(6)^{* *}$ & $-9(8)$ & $-19(4)^{* * *}$ \\
\hline During $\times \mathrm{T} \times \mathrm{LC}$ & $-19(8)^{* *}$ & $2(12)$ & $-19(16)$ & $-17(8)^{* *}$ \\
\hline During $\times \mathrm{T} \times \mathrm{SC}$ & $-3(8)$ & $5(10)$ & $-23(12)^{*}$ & $11(8)$ \\
\hline After $\times \mathrm{T}$ & $12(2)^{* * *}$ & $50(3)^{* * *}$ & $-43(11)^{* * *}$ & $15(3)^{* * *}$ \\
\hline After $\times \mathrm{T} \times \mathrm{BA}$ & $329(13)^{* * *}$ & $345(20)^{* * *}$ & $144(54)^{* * *}$ & $348(11)^{* * *}$ \\
\hline After $\times \mathrm{T} \times \mathrm{AA}$ & $153(7)^{* * *}$ & $101(11)^{* * *}$ & $188(16)^{* * *}$ & $103(6)^{* * *}$ \\
\hline After $\times \mathrm{T} \times \mathrm{LC}$ & $31(14)^{* *}$ & $136(21)^{* * *}$ & $108(27)^{* * *}$ & $39(14)^{* * *}$ \\
\hline After $\times \mathrm{T} \times \mathrm{SC}$ & $22(14)$ & $15(15)$ & $42(18)^{* *}$ & $-33(13)^{* * *}$ \\
\hline $\begin{array}{l}\text { Total college- } \\
\text { level credits } \\
\text { completed }\end{array}$ & $4(0)^{* * *}$ & $6(1)^{* * *}$ & $5(1)^{* * *}$ & $6(0) * * *$ \\
\hline Observations & 482,120 & 365,300 & 172,020 & 675,400 \\
\hline
\end{tabular}

Note. This table reports the sheepskin effects of credentials for key demographic subgroups based on Equation 7; each column represents a separate regression. Standard errors are in parentheses.

$* * * p<.01, * * p<.05, * p<.1$ 
Table 6. Estimates for the Three Piece Growth Curve Model by Field of Study (in 2010 Dollars)

\begin{tabular}{|c|c|c|c|c|c|c|c|}
\hline & $\begin{array}{l}\text { Humanities \& } \\
\text { Social Science }\end{array}$ & $\begin{array}{l}\text { Math \& } \\
\text { Science }\end{array}$ & Health & $\begin{array}{l}\text { Mechanics \& } \\
\text { Construction }\end{array}$ & $\begin{array}{c}\text { Public } \\
\text { Administration }\end{array}$ & Business & Education \\
\hline Intercept & $3,214(22)^{* * *}$ & $3,185(23) * * *$ & $3,153(23)^{* * *}$ & $3,158(23) * * *$ & $3,171(23) * * *$ & $3,180(23)^{* * *}$ & $3,171(23)^{* * *}$ \\
\hline Bachelor's (BA) & -162 (209) & $1,059(344)^{* * *}$ & $1,896(539)^{* * *}$ & N/A & $60(640)$ & $573(301)^{*}$ & $1,062(715)$ \\
\hline Associate (AA) & 95 (118) & $969(195)^{* * *}$ & $926(158)^{* * *}$ & 559 (363) & $4(221)$ & $944(190)^{* * *}$ & $-1,845(448)^{* * *}$ \\
\hline Long cert. (LC) & $574(321)^{*}$ & $-882(781)$ & 424 (249)* & $-333(288)$ & $-2,290(592)^{* * *}$ & $-1,601(984)$ & $490(755)$ \\
\hline Short cert. (SC) & $-1,406(1564)$ & $2,205(416)^{* * *}$ & $230(225)$ & 461 (307) & $-220(322)$ & $4,900(482)^{* * *}$ & -994 (626) \\
\hline During college & $154(19)^{* * *}$ & $147(19)^{* * *}$ & $141(19)^{* * *}$ & $134(19)^{* * *}$ & $141(19)^{* * *}$ & $147(19)^{* * *}$ & $142(19)^{* * *}$ \\
\hline During $\times$ BA & $-743(200)^{* * *}$ & $-1,731(329)^{* * *}$ & $-1,104(516)^{* *}$ & N/A & $-367(615)$ & $-792(285)^{* * *}$ & $-1,620(688)^{* *}$ \\
\hline During $\times$ AA & $-387(109)^{* * *}$ & $-899(179)^{* * *}$ & $-731(139)^{* * *}$ & $91(316)$ & -115 (196) & $-440(172)^{* *}$ & $589(403)$ \\
\hline During $\times$ LC & $-605(302)^{* *}$ & 665 (715) & $-692(220)^{* * *}$ & $-196(247)$ & $298(554)$ & $-654(767)$ & -972 (659) \\
\hline During $\times$ SC & $817(1440)$ & $-1035(355)^{* * *}$ & $-301(191)$ & 338 (248) & $-573(307)^{*}$ & $-892(359)^{* *}$ & $39(533)$ \\
\hline After college & $274(19)^{* * *}$ & $263(19)^{* * *}$ & $252(19)^{* * *}$ & $248(19)^{* * *}$ & $257(19)^{* * *}$ & $264(19)^{* * *}$ & $258(19)^{* * *}$ \\
\hline After $\times$ BA & 219 (207) & $259(344)$ & $560(535)$ & N/A & $658(636)$ & $666(296)^{* *}$ & $-825(714)$ \\
\hline After $\times$ AA & $-353(117)^{* * *}$ & $-621(192)^{* * *}$ & $850(148)^{* * *}$ & $912(334)^{* * *}$ & $-23(207)$ & $-442(186)^{* *}$ & $736(420)^{*}$ \\
\hline After $\times$ LC & $-366(332)$ & 713 (737) & $-67(232)$ & $791(259) * * *$ & 318 (557) & 334 (813) & $-1,219(720)^{*}$ \\
\hline After $\times$ SC & 2,901 (1489)* & $-1,252(376)^{* * *}$ & $-411(205)^{* *}$ & 400 (259) & $-168(276)$ & $-666(387)^{*}$ & $106(600)$ \\
\hline Time (T) & $64(1)^{* * *}$ & $64(1)^{* * *}$ & $62(1)^{* * *}$ & $63(1)^{* * *}$ & $63(1)^{* * *}$ & $64(1)^{* * *}$ & $63(1)^{* * *}$ \\
\hline $\mathrm{T} \times \mathrm{BA}$ & $-8(10)$ & $21(17)$ & $66(25)^{* * *}$ & N/A & $-4(32)$ & $12(15)$ & $44(34)$ \\
\hline $\mathrm{T} \times \mathrm{AA}$ & $-2(6)$ & $30(10)^{* * *}$ & $24(9)^{* * *}$ & $24(22)$ & $1(12)$ & $20(10)^{* *}$ & $-67(23)^{* * *}$ \\
\hline $\mathrm{T} \times \mathrm{LC}$ & 22 (16) & $-37(45)$ & $27(14)^{*}$ & $-2(20)$ & $-111(40)^{* * *}$ & $-57(63)$ & $63(43)$ \\
\hline $\mathrm{T} \times \mathrm{SC}$ & $-120(86)$ & $91(24)^{* * *}$ & $16(13)$ & $16(21)$ & $15(22)$ & $131(28)^{* * *}$ & $-9(33)$ \\
\hline During $\times \mathrm{T}$ & $-12(1)^{* * *}$ & $-12(1)^{* * *}$ & $-13(1)^{* * *}$ & $-13(1)^{* * *}$ & $-13(1)^{* * *}$ & $-12(1)^{* * *}$ & $-13(1)^{* * *}$ \\
\hline
\end{tabular}




\begin{tabular}{|c|c|c|c|c|c|c|c|}
\hline During $\times \mathrm{T} \times \mathrm{BA}$ & $-18(10)^{*}$ & $-62(16)^{* * *}$ & $-6(23)$ & N/A & $-5(30)$ & $-22(14)$ & $-47(32)$ \\
\hline During $\times \mathrm{T} \times \mathrm{AA}$ & $-12(5) * *$ & $-36(9)^{* * *}$ & $-21(7)^{* * *}$ & $8(18)$ & $6(10)$ & $-18(8)^{* *}$ & 31 (19) \\
\hline During $\times \mathrm{T} \times \mathrm{LC}$ & $-30(14)^{* *}$ & 24 (39) & $-18(12)$ & $28(18)$ & $21(39)$ & $-119(49)^{* *}$ & $-45(36)$ \\
\hline During $\times \mathrm{T} \times \mathrm{SC}$ & $87(75)$ & $-57(20)^{* * *}$ & $-8(11)$ & $50(19)^{* * *}$ & $-61(26)^{* *}$ & $-62(22)^{* * *}$ & $2(26)$ \\
\hline After $\times \mathrm{T}$ & $29(2)^{* * *}$ & $29(2)^{* * *}$ & $31(2)^{* * *}$ & $30(2)^{* * *}$ & $29(2)^{* * *}$ & $29(2)^{* * *}$ & $29(2)^{* * *}$ \\
\hline After $\times \mathrm{T} \times \mathrm{BA}$ & $316(17)^{* * *}$ & $390(28)^{* * *}$ & $381(43)^{* * *}$ & N/A & $364(50)^{* * *}$ & $264(24)^{* * *}$ & $298(61)^{* * *}$ \\
\hline After $\times \mathrm{T} \times \mathrm{AA}$ & $118(11)^{* * *}$ & $78(17)^{* * *}$ & $233(13)^{* * *}$ & $13(28)$ & $140(17)^{* * *}$ & $59(17)^{* * *}$ & $112(37)^{* * *}$ \\
\hline After $\times \mathrm{T} \times \mathrm{LC}$ & $-12(36)$ & $138(71)^{*}$ & $52(20) * * *$ & $118(25)^{* * *}$ & $186(51)^{* * *}$ & $4(83)$ & $-163(66)^{* *}$ \\
\hline After $\times \mathrm{T} \times \mathrm{SC}$ & $314(114)^{* * *}$ & $-21(37)$ & $59(20)^{* * *}$ & $-30(26)$ & $-18(30)$ & $-227(37)^{* * *}$ & $-26(56)$ \\
\hline $\begin{array}{l}\text { Total college-level } \\
\text { credits completed }\end{array}$ & $4(0)^{* * *}$ & $6(0) * * *$ & $8(0)^{* * *}$ & $8(0)^{* * *}$ & $7(0) * * *$ & $6(0)^{* * *}$ & $7(0)^{* * *}$ \\
\hline Observations & 688,641 & 620,183 & 631,926 & 597,712 & 603,798 & 621,688 & 594,390 \\
\hline
\end{tabular}

Note. Estimates are based on Equation 7; each column represents a separate regression. Standard errors are in parentheses.

$* * * p<.01, * * p<.05, * p<.1$ 
In contrast, among younger students, only non-awardees and associate degrees awardees experienced the reverse Ashenfelter dip, and given their strong increases in earnings growth over time, associate degree earners overcame this deficit within another quarter or two. Among both age groups, short certificates appeared to provide poor returns; for example, while short certificates provided immediate returns for younger students (\$233, or $-\$ 68+\$ 301)$, these students' growth in earnings was estimated at -\$18 per quarter (or \$15 - \$33); thus their investment in the short certificate seemed unlikely to pay off over the long term.

Another differential is apparent among older versus younger students who would eventually earn bachelor's degrees. Among younger students, eventual bachelor awardees had the lowest estimated non-college earning levels; while among older students, eventual bachelor awardees had the highest non-college earning levels. This finding provides some support to the notion that younger students who will eventually earn a bachelor's degree have pre-enrollment earnings that may not adequately capture their pre-existing human capital. Although all wage records in the dataset are for quarters in which students are 18 and older (that is, these younger students' low earnings are unlikely to be due to high school attendance), these individuals may choose to be underemployed as they prepare to focus on their college career. Indeed, given the penalties of labor market attachment in terms of college academic performance, these students' underemployment may assist them in persisting through college toward their eventual award (Dadgar, 2012; DeSimone, 2008; Kalenkoski \& Pabilonia, 2010; Stinebrickner \& Stinebrickner, 2003). If so, then models that control for these younger students' pre-enrollment earnings are likely to overestimate the returns to bachelor's degree awards.

In terms of field of study, the three-piece GCM model suggests that students who earned most types of bachelor's degree-humanities and social science, math and science, health, public administration, and education-experienced similar immediate post-exit returns compared with non-awardees; only bachelor's degree earners in business experienced significantly stronger immediate returns than non-awardees. However, all types of bachelor's degree awardees experienced significantly stronger returns in post-exit earnings growth, compared with nonawardees. For associate degrees, results were mixed across fields. Compared with non-awardees, associate degrees in health (popular among women) seemed to provide strong returns both in terms of an immediate bump (\$850 higher) and earnings growth (an additional \$233 per quarter), and associate degrees in mechanics and construction (popular among men) provided a strong immediate return (\$912 higher) but no additional earnings growth. Compared with nonawardees, associate degree awardees in education also experienced stronger immediate returns (\$736 higher) and stronger increases in earnings growth (an additional \$112 per quarter). The remaining associate degrees provided neutral or negative immediate returns compared with nonawardees, but all (with the exception of mechanics and construction) provided at least a mild degree of additional earnings growth over time.

For long certificates, mechanics and construction was the only field to provide a stronger immediate post-exit bump in comparison with non-awardees; this field, as well as math and 
science, health, and public administration also provided additional earnings gains, while the remaining fields did not. Among long certificates, the most disheartening results were for the field of education, in which awardees experienced an immediate earnings penalty, as well as flat earnings across time (an estimated growth of $-\$ 8$ per quarter, or $\$ 63+\$ 63+\$ 29-\$ 163$ ).

In terms of short certificates, only humanities and social science awards provided an immediate positive return in comparison with non-awardees, and only this field as well as health provided additional earnings gains across time. The most negative results for short certificates were in math and science as well as business. However, short-certificate awardees in these fields were unusually highly compensated prior to college enrollment, with high non-college earnings levels ( $\$ 5,390$ for math and science awardees and $\$ 8,080$ for business awardees, compared with \$3,615 for the typical eventual short-certificate awardee) and non-college earnings growth (\$155 per quarter for math and science awardees and $\$ 195$ per quarter for business awardees, compared with $\$ 79$ for the typical eventual short-certificate awardee). Thus despite the negative returns to their awards, these students maintained relatively high earnings after graduation: math and science short-certificate awardees earned an estimated \$4,401 in the quarter immediately after graduation with a post-award earnings growth of $\$ 163$ per quarter, while business shortcertificate awardees earned an estimated $\$ 7,678$ in the quarter immediately after graduation with a flat growth of $-\$ 3$ per quarter (compared with a typical short certificate post-award profile of \$4,011 and \$111). This observation accords with Xu and Trimble’s (2014) speculation that negative returns to some certificates may be due to workers who choose to move from relatively lucrative fields into new areas that provide more employment stability, better hours or benefits, or more personal fulfillment.

\section{Implications for Traditional and Evolving Econometric Models}

Our results provide insight on the validity of three assumptions that underpin most approaches to analyzing returns to community college awards: that across-student variation is constant across time, that the model specifies a counterfactual that is appropriate for all members of the sample, and that the impacts of a given award are fixed across time.

\subsection{The Assumption That Across-Student Variation Is Constant Across Time}

Key to identification of the individual fixed-effects model is the assumption that there are no factors varying within students across time that are related to students' educational choices as well as to their labor market outcomes. Our results suggest that this assumption is almost certainly not met in datasets such as ours: for example, students who would eventually complete short certificates in math and science or business demonstrated very different pre- and duringenrollment earnings trajectories compared with those who would earn short certificates in other fields. 
In studies using the individual fixed-effects approach, the most common method of addressing the assumption that across-student variation is constant across time is to allow the effects of time to vary across student groupings based on selected observable characteristics. In contrast, our approach allowed the effects of time to vary across all students; in a parallel to the individual fixed-effects strategy, however, we also introduced selected student observables at the second level of the model, allowing us to observe how the effects of time varied across these groups. Our Level 2 student predictors were indeed successful in explaining time-varying acrossstudent variation: our two-piece model, which was most similar to the specification of an individual fixed-effects model, explained more than a third of the across-student variation in earnings across time. Moreover, our two- and three-piece specifications for growth were more flexible than is typical in individual fixed-effects models, which allowed us to explain acrossstudent variation in true individual growth at both the pre-enrollment and during-enrollment time periods more precisely than could a less-flexible model. Even so, we certainly did not explain all time-varying across-student variation, and indeed, it may be impossible to do so, given that individuals are uniquely distinct in how they develop and change across time. Accordingly, rather than futilely attempting to control away this variation, the GCM approach models it, describes it, quantifies how much we are able to explain and how much we are not, and allows analysts to interpret its results within that context.

The GCM approach to dealing with time-varying across-student variation is more transparent and candid about its limitations, and thus may ultimately be more informative and useful. However, its results are also somewhat more complex to interpret than the single estimate provided by a Mincerian approach. Accordingly, our results also suggest another strategy for dealing with variation in individual growth curves: as a first step in a Mincerian model, analysts could estimate individual pre- and during-enrollment earnings growth. While these estimates can be calculated using OLS, analysts can also take advantage of GCM's Bayesian estimation approach by calculating individual growth estimates using GCM software (such as the package used in our analyses, SAS Proc Mixed, SAS Institute, 2014). Analysts could then use those individual growth estimates as controls in the model, echoing the approach of Ashenfelter and Card (1985).

\subsection{The Assumption of an Appropriate Counterfactual}

The typical individual fixed-effects or difference-in-differences model compares students' earnings before and after the awarding of a credential, an approach that assumes that both pre- and during-enrollment data represent the appropriate comparison for post-exit outcomes. Yet students' earning trajectories during enrollment may be confounded with their eventual outcomes: in our study, students who would eventually fail to earn an award, or who would earn a short certificate, seemed to remain more strongly attached to the labor market during their enrollment in comparison with those who would eventually earn longer term credentials. 
Our three-piece model defined an alternative counterfactual by estimating students' earnings trajectories across the pre-exit timeframe had they never enrolled in college at all. This counterfactual is likely appropriate for many students - those whose pre-enrollment earnings accurately reflect their earnings potential—but may be inappropriate for younger students who will eventually earn a bachelor's degree. Such students may choose to be underemployed in order to focus more fully on school, and thus their pre-enrollment (and during-enrollment) earnings may be confounded with their eventual success in earning a reward.

Overall, there may be no counterfactual appropriate to all the students in a community college dataset. If so, however, then the GCM approach may be more informative than traditional econometric approaches. Because Mincerian and individual fixed-effects approaches focus on estimating a single increment of pre-post change and attempt to control away any remaining variation, these models tend to obscure useful information regarding students' preenrollment and during-enrollment earnings patterns. In contrast, the GCM approach brings preenrollment and during-enrollment earnings patterns into sharp focus, allowing the analyst to describe potentially confounding patterns and more clearly understand the extent to which they may bias estimates of returns.

On a similar note, GCM's focus on not just the increment of change due to an award, but also on the pre- and post-award trajectories that represent the larger context of that change, can provide insights that are useful for policy and practice applications. For example, in this paper we highlighted two short certificates with negative returns: those in math and science and those in business. A Mincerian or individual fixed-effects analysis would conclude only that these awards resulted in a negative change in earnings-information that may lead analysts and policymakers to denounce such programs as inferior. Yet in our study, we observed that students who chose these awards left behind relatively lucrative salaries in order to enter these new fields, and thus still maintained moderately high earnings even after suffering an earnings penalty. We do not have any information as to why these students made the choice to move to a lower earning field-perhaps they were swayed by other benefits, such as more stability, more flexible working hours, or more personally rewarding work-but situating the estimated negative return within the larger context of their earnings profile does help us more clearly understand the context and implications of student choice, and certainly makes us hesitant to label these awards as disadvantageous.

\subsection{The Assumption That the Impacts of an Award Are Fixed Over Time}

Our analyses demonstrate that awards differ not just in terms of their impact on earnings levels but also in their impact on growth in earnings across time. Accordingly, if stakeholders focus on earnings outcomes at one or two years versus five or six years post-award, they may draw very different conclusions regarding the value of different credentials. For example, consider a prospective student who is trying to decide between pursuing a bachelor's degree in business or in math and science. Based on our models, the immediate returns to business are 
larger: compared with a non-awardee, a business graduate is estimated to earn \$666 more in the quarter immediately after graduation, while a math and science major would earn only a nonstatistically significant \$259 more. Yet, the post-award earnings growth for math and science graduates is stronger: compared with non-awardees, business graduates experience an additional growth of \$264 per quarter, while math and science graduates experience an additional growth of $\$ 390$ per quarter. As a result, in just five quarters the returns to math and science bachelor's degrees would outstrip those of business, and would continue to become even stronger over the long term.

Econometricians using Mincerian and fixed-effects approaches could deal with this problem in at least two ways. First, analysts could add interactions between time and credentials to allow for variations in returns over time; or for a clearer interpretation of the findings, they could follow Liu et al.'s (2015) approach of calculating returns to awards at several different points in time. When following this strategy, however, it would be much more informative to calculate returns based on specific post-exit times, rather than specific post-entry times, as Liu and colleagues do. Second, following Jacobson et al. (2005), analysts could include a control such as $\left(\frac{1}{t_{\text {-leave }}}\right)$, which alters the interpretation of the model's award coefficient to represent long-run returns. Under this approach, however, it is unclear how "long-run” returns are defined: How many quarters or years must a student work after graduation in order to reach the long-run estimate? And from a practical perspective, can students expect their earnings to further increase or to flatten after this point? The GCM approach provides more clarity in terms of immediate benefits to an award, as well as to how those benefits change across time. Using our approach, one can calculate returns at any given point post-exit-although since most students in our sample were tracked for only three years post-exit, we would be reluctant to extend the estimated trajectory much past that point.

\section{Implications for Policy and Practice}

In addition to providing methodological insights for econometricians, we are concerned with providing useful information to policymakers, community college practitioners, and students themselves. While our full three-piece GCM is far too complex for practical application, a simpler version of the same concept could be quite useful for both performance-based policy formulas and for student advising purposes.

Within state systems that practice ongoing UI matching, state or institutional research officers would require only minimal statistical training in order to calculate OLS-based withinstudent earnings trajectories. For example, after discarding students still enrolled in college or graduate school, analysts could calculate a pre-entry intercept and linear slope for each awardee's pre-enrollment period, and a post-exit intercept and linear slope for each awardee's post-exit period. For performance funding purposes, the differential between the two intercepts, 
as well as the differential between the two slopes, could be included in policy formulas. While crude, and certainly open to the objection that pre-enrollment trajectories may not be an appropriate counterfactual for young bachelor's degree earners, such metrics would likely be more precise and informative than those currently in use. In particular, calculating the slope differential would help sidestep the thorny problem of when to calculate labor market returns, given that short- versus long-term calculations may result in very different conclusions in terms of which programs provide the "best" returns.

We would caution, however, that programs which appear to have negative labor market returns may provide students with other important benefits; indeed, if a student chooses to move from a higher paying to a lower paying field, there is likely a good reason underlying that choice. Accordingly, policymakers may wish to impose a floor and treat negative returns as zero returns, in order to avoid penalizing colleges for providing programs that students may value for reasons other than boosting earnings. Moreover, states wishing to use UI data for accountability purposes may find it useful to establish UI data-sharing agreements with neighboring states, as well as states that tend to attract large numbers of out-of-state employees. Although there is scant research on this topic, students who cross state lines may do so because they can find more lucrative positions outside the state; if so, excluding these students may penalize programs that are successful in placing their graduates in well-paying jobs across the country.

For purposes of student advisement, OLS-based intercepts and slopes could easily be aggregated in a variety of flexible ways - for example, by college, field, student age, year of graduation, or any other student characteristic of interest - and then depicted graphically (similar to Figure 1) or portrayed in tabular form (similar to the two-piece results in Table 4). As an alternative to graphing the intercept and slope, colleges might choose to display the OLS-based one-, three-, five-, and even 10-year post-award estimated earnings (if post-exit tracking extends that far), allowing students to more readily understand and plan for the short- and long-term financial implications of their program choice.

\section{Conclusion}

Overall, our results are broadly consistent with those of existing analyses comparing community college awardees with non-awardees (e.g., Bahr, 2014; Bailey et al., 2004; Dadgar \& Weiss, 2014; Jepsen et al., 2014; Liu et al., 2015; Xu \& Trimble, 2014), in that bachelor's degrees tended to yield substantial labor market returns, associate degrees tended to yield moderate returns, and certificates tended to yield very mixed returns based on field of study. However, using a growth curve analysis to model individual wage growth as a dynamic process helps shed light on the complexities involved in estimating the labor market returns to an education credential. For example, while traditional analyses tend to focus on short-term increases in earnings levels, our three-piece growth curve model suggests that over the span of 
several years, the bulk of positive returns are due not to immediate increases in earnings levels but rather to increases in awardees' earnings growth across time. While some associate degree fields yielded null or negative immediate returns, these awards also yielded increases in awardees' rate of earnings growth, resulting in positive estimated returns within two years, as well as even stronger returns in subsequent years. Of course, our analysis is limited by a followup timeframe of only a few years, and the impact of education may vary substantially over the life-cycle (Hanushek, Woessmann, \& Zhang, 2011). Accordingly, future studies may wish to further explore individual earnings growth curves using datasets with longer post-college timeframes.

Our results also suggest that three key assumptions underpinning typical approaches to the analysis of labor market returns to community college credentials - that across-student variation is constant across time, that the model specifies a counterfactual that is appropriate for all members of the sample, and that the impacts of a given award are fixed across time-may not be well founded. We have argued that the GCM approach allows analysts to be more transparent and candid about the extent to which these assumptions are violated, and thus how they may bias estimates of labor market returns. For analysts that prefer the relative simplicity of the single estimate yielded by Mincerian or individual fixed-effects approaches, however, we have provided several recommendations that may help strengthen the results obtained through these approaches. 


\section{References}

Abadie, A. (2005). Semiparametric difference-in-difference estimators. The Review of Economic Studies, 72(1), 1-19.

Ashenfelter, O. (1978). Estimating the effect of training programs on earnings. The Review of Economics and Statistics, 60(1), 47-57.

Ashenfelter, O., \& Card, D. (1985). Using the longitudinal structure of earnings to estimate the effect of training programs. The Review of Economics and Statistics, 67(4), 648-660.

Bahr, P. R. (2014). The labor market return in earnings to community college credits and credentials in California. Retrieved from University of Michigan website: https://umich.app.box.com/Bahr-2014-earnings1

Bailey, T., Jaggars, S. S., \& Jenkins, D. (2015, forthcoming). Redesigning America's community colleges: A clearer path to student success. Cambridge, MA: Harvard University Press.

Bailey, T., Kienzl, G. S., \& Marcotte, D. E. (2004). The returns to a sub-baccalaureate education: The effects of schooling, credentials, and program of study on economic outcomes. New York, NY: Columbia University, Teachers College, Community College Research Center.

Belfield, C., \& Bailey, T. (2011). The benefits of attending community college: A review of the evidence. Community College Review, 39(1), 46-68.

Burstein, L., Linn, R., \& Capell, F. J. (1978). Analyzing multilevel data in the presence of heterogeneous within-class regressions. Journal of Educational Statistics, 3, 347-383.

Crosta, P. M. (2014). Intensity and attachment: How the chaotic enrollment patterns of community college students relate to educational outcomes. Community College Review, 42(2), 118-142.

Dadgar, M. (2012). The academic consequences of employment for students enrolled in community college (CCRC Working Paper No. 46). New York, NY: Columbia University, Teachers College, Community College Research Center.

Dadgar, M., \& Trimble, M. J (2014). Labor market returns to sub-baccalaureate credentials: How much does a community college degree or certificate pay? Educational Evaluation and Policy Analysis. Advance online publication. doi:10.3102/0162373714553814

DeSimone, J. S. (2008). The impact of employment during school on college student academic performance (NBER Working Paper No. 14006). Cambridge, MA: National Bureau of Economic Research.

Dougherty, K. J., \& Reddy, V. (Eds.). (2013). Performance funding for higher education: What are the mechanisms? What are the impacts? ASHE Higher Education Report, 39(2). 
Florida Board of Governors. (2013). Press release: Board of Governors releases performance funding to universities. Retrieved from http://www.flbog.edu/pressroom/news.php?id=509

Heckman, J., Lalonde, R., \& Smith, J. (1999). The economics and cconometrics of active labor market programs. In O. Ashenfelter \& D. Cards (Eds.), Handbook of labor economics: Volume $3 a$ (pp. 1865-2085). New York, NY: Elsevier.

Hanushek, E. A., Woessmann, L., \& Zhang, L. (2011). General education, vocational education, and labor-market outcomes over the life-cycle (NBER Working Paper No. 17504). Cambridge, MA: National Bureau of Economic Research.

Horn, L. (2010). Tracking students to 200 percent of normal time: Effect on institutional graduation rates (NCES 2011-221). Washington, DC: U.S. Department of Education, Institute of Education Sciences, National Center for Education Statistics.

Horn, L., \& Neville, S. (2006). Profile of undergraduates in U.S. postsecondary education institutions, 2003-04: With a special analysis of community college students (NCES 2006-184). Washington, DC: U.S. Department of Education, Institute of Education Sciences, National Center for Education Statistics.

Jacobson, L., LaLonde, R., \& Sullivan, D. (2005). Estimating the returns to community college schooling for displaced workers. Journal of Econometrics, 125, 271-304.

Jepsen, C., Troske, K., \& Coomes, P. (2014). The labor-market returns to community college degrees, diplomas, and certificates. Journal of Labor Economics, 32(1), 95-121.

Jones, D. P. (2013). Outcomes-based funding: The wave of implementation. Washington, DC: Complete College America and the National Center for Higher Education Management Systems.

Kalenkoski, C. M., \& Pabilonia, S. W. (2010). Parental transfers, student achievement, and the labor supply of college students. Journal of Population Economics, 23(2), 469-496.

Kelderman, E. (2013, January 3). College education is expected to remain a high priority for states. Chronicle of Higher Education. Retrieved from http://chronicle.com/article/College-Education-Is-Expected/136427/

Liu, Y. T., Belfield, C. R, \& Trimble, M. J. (2015). The medium-term labor market returns to community college awards: Evidence from North Carolina. Economics of Education Review, 44, 42-45. [A prior version of this paper is available from http://capseecenter.org/medium-term-labor-market-return-to-community-collegeawards/.]

McArdle, J. J., \& Epstein, D. (1987). Latent growth curves within developmental structural equation models. Child Development, 58, 110-133. 
Mincer, J. (1974). Schooling, experience, and earnings. Cambridge, MA: National Bureau of Economic Research.

Minnesota State Legislature. (2013). Conference committee report on S.F. No. 1236, lines 11.16-11.23, https://www.revisor.mn.gov/bills/text.php?number=SF1236\&version=0\&session=ls88\&s ession_year $=2013 \&$ session_number $=0 \&$ type $=$ ccr

Perry, P. (2014). California community colleges: Salary surfer. Presentation at the conference of the Center for the Analysis of Postsecondary Education and Employment, September 2014, Washington, DC. Retrieved from http://capseecenter.org/2014conference/downloads/

Radford, A. W., Berkner, L., Wheeless, S. C., \& Shepherd, B. (2010). Persistence and attainment of 2003-04 beginning postsecondary students: After 6 years (NCES 2011-151). Washington, DC: U.S. Department of Education, Institute of Education Sciences, National Center for Education Statistics.

Raudenbush, S. W., \& Bryk, A. S. (2002). Hierarchical linear models ( ${ }^{\text {nd }}$ ed). Thousand Oaks: CA: Sage Publications.

Reeser, M. (2014). Value-added accountability funding: An innovative funding model launched in Texas. Presentation at the conference of the Center for the Analysis of Postsecondary Education and Employment, September 2014, Washington, DC. Retrieved from http://capseecenter.org/2014-conference/downloads/

SAS Institute. (2014). SAS/STAT 13.2 user's guide. Cary, NC: SAS Institute.

Singer, J. D., \& Willett, J. B. (2003). Applied longitudinal data analysis: Modeling change and event occurrence. New York, NY: Oxford University Press.

Snyder, T. D., \& Dillow, S. A. (2012). Digest of education statistics 2011 (NCES 2012-001). Washington, DC: U.S. Department of Education, Institute of Education Sciences, National Center for Education Statistics.

Stinebrickner, R., \& Stinebrickner, T. R. (2003). Working during school and academic performance. Journal of Labor Economics, 21(2), 473-491.

Texas Higher Education Coordinating Board. (2013). Texas State Technical College System returned value funding model methodology. Retrieved from THECB website: http://www.thecb.state.tx.us/reports/pdf/3207.pdf

Willett, J. B. (1997). Measuring change: What individual growth modeling buys you. In E. Amsel \& A. Renninger (Eds.), Change and development: Issues of theory, method, and application (pp. 213-243). Mahwah, NJ: Erlbaum.

Wooldridge, J. (2002). Econometric analysis of cross section and panel data. Cambridge, MA: MIT Press. 
Xu, D., \& Trimble, M. J. (2014). What about certificates? Evidence on the labor market returns to non-degree community college awards in two states. New York, NY: Columbia University, Teachers College, Community College Research Center.

Zeger, S. L., \& Liang, K.-Y. (1986). Longitudinal data analysis for discrete and continuous outcomes. Biometrics, 42, 121-130. 